\title{
Microstructure and Property Evolution in Advanced Cladding and Duct Materials Under Long-Term Irradiation at Elevated Temperature: Critical Experiments
}

Reactor Concepts RD\&D

Dr. Gary Was

University of Michigan

In collaboration with:

University of Florida University of Wisconsin-Madison

Sue Lesica, Federal POC Lizhen Tan, Technical POC

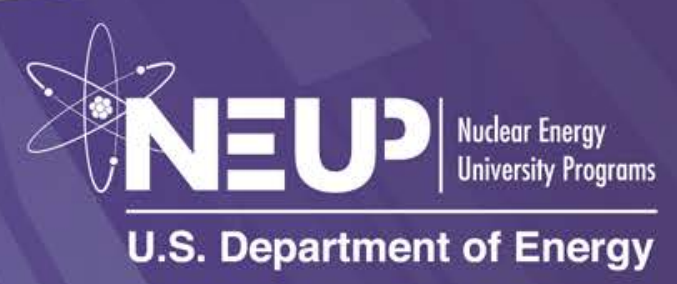




\section{FINAL REPORT}

Project Title: $\quad$ Microstructure and Property Evolution in Advanced Cladding and Duct Materials under Long-term and Elevated Temperature: Critical Experiments

Covering Period: $\quad$ October 1, 2010-September 31, 2013

Date of Report: $\quad$ December 20, 2013

Recipient: $\quad$ University of Michigan

2355 Bonisteel Blvd

Ann Arbor, MI 48109-2104

Award Number: $\quad$ DE-AC07-05ID14517

Project Number: $\quad$ 10-172 (10-678)

Principle Investigator: Gary S. Was, 734-763-4675

Working Partners: $\quad$ Zhijie Jiao, University of Michigan, zjiao@umich.edu Todd Allen, University of Wisconsin, allen@engr.wisc.edu Yong Yang, University of Florida, yongyang@ufl.edu

Project Objective: To extend the range of operation of nuclear fuel cladding and structural materials in advanced nuclear energy and transmutation systems to that required for the fast reactor, the irradiation-induced evolution of the microstructure, microchemistry, and the associated mechanical properties at relevant temperatures and doses must be understood. This project performs a set of critical experiments to improve the understanding of these radiation effects.

Project Goals: $\quad$ 1) Identify the formation mechanism and evolution for dislocation loops with Burgers vector of $a<100>$ and determine whether the defect microstructure saturates at high dose and identify whether a threshold irradiation temperature or dose exists for the nucleation of growing voids that mark the beginning of irradiation-induced swelling, and begin to probe the limits of thermal stability of the tempered martensitic structure under irradiation, 2) evaluate the stability of nanometer sized YTi- O based ODS particles at high fluence/temperature, 3) evaluate the extent to which precipitates form and/or dissolve as a function of irradiation temperature and dose, 4) how these changes are driven by radiation induced segregation, neighboring microchemical evolution, and initial microstructure, and 5) identify the mechanisms of irradiation creep in ferritic-martensitic steels. 


\section{Executive Summary}

The major accomplishments of this project are as follows:

- Dislocation loops in ion irradiated F-M alloys are dominated by $<100>$ type loops at high doses and at low doses, defect clusters and small loops (both $<100>$ and $1 / 2<111>$ type) exist.

- There is a clear dependence of dislocations on irradiation temperature with dislocation loops dominant at low temperature and dislocation segments and network dominant at high temperature. Dislocation loops saturate at $\sim 100$ dpa for the $9 \mathrm{Cr}$ model alloy. Dislocation loops appear to be larger and with a number lower density at 500 dpa for T91 and HCM12A.

- $\mathrm{Ni} / \mathrm{Si} / \mathrm{Mn}$-rich, $\mathrm{Cu}$-rich and $\mathrm{Cr}$-rich precipitates are three commonly observed radiationinduced or enhanced precipitates in ion-irradiated F-M alloys. The type of precipitates is heavily dependent on alloy composition.

- Irradiation temperature has a significant effect on precipitates. Precipitates are larger and at lower number density in high temperature irradiations.

- There is an incubation dose for precipitate nucleation in ion irradiated F-M alloys. Precipitate coarsening occurred at high doses. A high volume fraction of radiation-induced carbides observed in F-M alloys occurs high dose and high temperature.

- The stability of Yi-Y-O nanoclusters $14 \mathrm{YWT}$ ferritic ODS steel under $5 \mathrm{MeV} \mathrm{Ni}^{2+}$ irradiation to $100 \mathrm{dpa}$ and at $-75^{\circ} \mathrm{C}, 100^{\circ} \mathrm{C}, 300^{\circ} \mathrm{C}, 450^{\circ} \mathrm{C}, 600^{\circ} \mathrm{C}$, and $700^{\circ} \mathrm{C}$ was examined. Heavy ion Irradiation under $300^{\circ} \mathrm{C}$ leads to a substantial decrease in size and number density of nanoclusters in 14YWT. There are minimal changes in size and number density of nanoclusters in $14 \mathrm{YWT}$ irradiated at $450^{\circ} \mathrm{C}$ to $600^{\circ} \mathrm{C}$ compared to the unirradiated case.

- Irradiation at $-50^{\circ} \mathrm{C}$ and $200^{\circ} \mathrm{C}$ leads to an apparent decrease in the average size and the number density of nanocusters in the 9Cr-ODS. Change in size and density is much less for samples irradiated at $600^{\circ} \mathrm{C}$. A slight coarsening of nanoclusters in the $9 \mathrm{Cr}$-ODS was observed as a result of proton irradiation at $400^{\circ} \mathrm{C}$ to $3.7 \mathrm{dpa}$.

- The behavior of $\mathrm{Cr}$ (and Fe) RIS in F-M alloys was found to be largely consistent with the IK mechanism, supporting IK as the dominant mechanism of Cr RIS in F-M alloys.

- Dislocation loops nucleate anisotropically within a single grain depending on the angle between its habit plane and the tensile axis.

- Dislocation loop sizes correlate with stress and dose.

- SIPN contribution to strain accounts for $6-37 \%$ of the total strain measured. The longer the irradiation, the less SIPN contributes to the total strain.

- Stress dependence of irradiation creep is linear at stress below $160 \mathrm{MPa}$ and greater than linear at stress above $160 \mathrm{MPa}$, suggesting a switch from dislocation climb to dislocation glide at higher stress. 


\section{Major Accomplishments}

The following sections describe the major accomplishments or outcomes in this program. They are presented in a form that focuses on the key results and conclusions. Details of the experiments and full set of results are available in the quarterly reports and are referenced herein rather than repeated.

\subsection{Dislocation Microstructure}

Dislocation structures in irradiated Ferritic/Martensitic alloys were fully characterized in terms of dose and temperature. The studied alloys included T91, NF616, HCM12A, 9Cr and $12 \mathrm{Cr}$ model alloys. The heavy ion irradiation experiments were conducted using the 1.7MV Tandetron accelerator in the Michigan Ion Beam Laboratory (MIBL) at the University of Michigan. Samples were irradiated over a range of $7-500 \mathrm{dpa}$ and at temperatures of $400-500^{\circ} \mathrm{C}$ using 5 $\mathrm{MeV} \mathrm{Fe}{ }^{++}$. The temperature variation was monitored using a thermal imager and was kept within $\pm 10^{\circ} \mathrm{C}$ during the course of irradiation. The dose rate was $\sim 10^{-3} \mathrm{dpa} / \mathrm{s}$. The irradiation depth for 5 $\mathrm{MeV} \mathrm{Fe}{ }^{++}$in is $\sim 1.2 \mu \mathrm{m}$ according to SRIM calculation (full cascade mode). Low dose proton irradiations (1-3dpa) were conducted at the University of Wisconsin's ion beam lab with 2.0 $\mathrm{MeV}$ protons, and the dose rate was approximate $1.3 \times 10^{-5} \mathrm{dpa} / \mathrm{s}$. The radiation damage peak is about $18 \mu \mathrm{m}$ below the surface, and the TEM specimens were prepared at the depth of $15 \mu \mathrm{m}$. The characterization of dislocation loops was performed using two beam bright field/dark field TEM images or STEM bright field images with the incident beam along the direction of [001] zone axis.

Dislocation loops in ion irradiated F-M alloys are dominated by $<100>$ type loops at high doses and at low doses, defect clusters and small loops (both $<100>$ and $1 / 2<111>$ type) exist.

For the irradiated $\mathrm{T} 91$ and $\mathrm{HCM} 12 \mathrm{~A}$ at $400^{\circ} \mathrm{C}$ or above to doses in the range 7-500 dpa, both the two beam condition TEM, and [001] zone axis STEM images show that the $<100>$ type dislocations loops are dominating while the $1 / 2<111>$ type dislocation loops are negligible, Figure 1. For the irradiated 9 and $12 \mathrm{Cr}$ model alloys, both $<100>$ and the $1 / 2<111>$ type dislocation loops are identified as the $1 / 2<111>$ type dislocation loops appear as ellipsoidal loops in a TEM image using $\mathrm{g}_{011}$ near the zone axis of [100]. However, the exact ratio between the $1 / 2<111>$ and $<100>$ type dislocation loops was not determined due to the fact that some dislocation loops are too small to be identified for their types. For NF616 irradiated at 500 and $700^{\circ} \mathrm{C}$, it was assumed that all the dislocation loops should be $<100>$ type since at such high temperature, the $1 / 2<111>$ type dislocation loops can easily migrate and annihilate at line dislocations, grain boundaries or other defect sinks. For the NF616 irradiated at $500^{\circ} \mathrm{C}$, the irradiated microstructures consisted of small clusters $(<5 \mathrm{~nm})$ and identifiable dislocation loops. However, for NF616 irradiated at $700^{\circ} \mathrm{C}$, the dislocations were mainly segments or networks.

There is a clear dependence of dislocations on irradiation temperature with dislocation loops dominant at low temperature and dislocation segments and network dominant at high temperature. 
Figure 2 shows dislocation evolution in T91 with increasing irradiation temperature. At $400^{\circ} \mathrm{C}$, the dominant feature in the irradiated microstructure is small dislocation loops (Figure 2a). The dislocation microstructure of $\mathrm{T} 91$ irradiated to $30 \mathrm{dpa}$ at $440^{\circ} \mathrm{C}$ contains a combination of dislocation loops and line dislocations (Figure 2b).. Dislocation loops are absent in T91 irradiated to $100 \mathrm{dpa}$ at $500^{\circ} \mathrm{C}$ and line dislocations become dominating feature (Figure $2 \mathrm{c}$ ). The effect of temperature on dislocation microstructure of T91 is very distinct with three different regimes: dislocation loops dominant $\left(400^{\circ} \mathrm{C}\right.$ and probably below), a combination of dislocation loops and dislocation segments $\left(440^{\circ} \mathrm{C}\right)$, and dislocation segments dominant $\left(500^{\circ} \mathrm{C}\right.$ and probably above). In $\mathrm{HCM} 12 \mathrm{~A}$, dislocation loops are also dominant at $400^{\circ} \mathrm{C}$ (Figure $3 \mathrm{a}$ ) and dislocation segments appear at $500^{\circ} \mathrm{C}$ (Figure 3b).

The transition of dislocation structures from loops to lines in irradiated NF616 is also very distinct as shown in Figure 4. The sample irradiated at $500^{\circ} \mathrm{C}$ contains a mixture of dislocation segment and dislocation loops, while at $700^{\circ} \mathrm{C}$ the dislocation network becomes a dominating feature.

For irradiated 9 and $12 \mathrm{Cr}$ model alloys, since the irradiation was only conducted at $400^{\circ} \mathrm{C}$, no temperature dependence can be deduced. However, it is confirmed again that the dislocation loops are the dominant dislocation structure in the materials irradiated at such temperature, as shown in Figure 5.

\section{Dislocation loops saturate at $\sim 100$ dpa for the $9 \mathrm{Cr}$ model alloy. Dislocation loops appear larger at lower density at 500 dpa for T91 and HCM12A.}

Dose dependence of dislocation loop is summarized in Figure 6. For T91 (Figure 6a), the number density of dislocation loops doubled between $30 \mathrm{dpa}\left(0.6 \times 10^{22} \mathrm{~m}^{-3}\right)$ and $100 \mathrm{dpa}\left(1.3 \times 10^{22} \mathrm{~m}^{-3}\right)$, but the average loop size was nearly the same at around $15 \mathrm{~nm}$. The average loop size increased to $27 \mathrm{~nm}$ and the number density decreased to $0.7 \times 10^{22} \mathrm{~m}^{-3}$ at $500 \mathrm{dpa}$. Although both size and number density changed significantly, dislocation loops are still the dominant microstructure at 500 dpa. Similar dose dependence holds for HCM12A irradiated at $400^{\circ} \mathrm{C}$ (Figure 6b). Density increased and the size was nearly unchanged at $100 \mathrm{dpa}$ compared to $30 \mathrm{dpa}$. The size increased from $13 \mathrm{~nm}$ at $100 \mathrm{dpa}$ to $22 \mathrm{~nm}$ at $500 \mathrm{dpa}$, while the number density decreased slightly from $1.5 \times 10^{22} \mathrm{~m}^{-3}$ to $1.4 \times 10^{22} \mathrm{~m}^{-3}$. In proton irradiated $\mathrm{NF} 616$ at $500^{\circ} \mathrm{C}$, both the average dislocation loop size and number density start to saturate at 2 dpa (Figure $6 \mathrm{c}$ ). For the $\mathrm{Fe}^{++}$irradiated $9 \mathrm{Cr}$, the similar saturation behavior of dislocation loop structure was observed. The changes of loop density and average dislocation loop size are minimal after 30 dpa (Figure 6d). 
Table 1 Summary of size and density of dislocation loops in irradiated alloys.

\begin{tabular}{|c|c|c|c|c|c|c|}
\hline Alloy & $\begin{array}{l}\text { Temp. } \\
\left({ }^{\circ} \mathrm{C}\right)\end{array}$ & $\begin{array}{l}\text { Dose } \\
\text { (dpa) }\end{array}$ & $\begin{array}{c}\text { \# of dislocation } \\
\text { loops }\end{array}$ & $\begin{array}{l}\text { Size } \\
(\mathrm{nm})\end{array}$ & $\begin{array}{l}\text { Density } \\
\left(10^{22} \mathrm{~m}^{-3}\right)\end{array}$ & Note \\
\hline \multirow{5}{*}{ T91 } & \multirow{4}{*}{400} & 7 & \multicolumn{4}{|l|}{ Defect clusters } \\
\hline & & 30 & 222 & $15.6 \pm 0.4$ & 0.6 & \multirow{3}{*}{$\begin{array}{l}\text { 100> type } \\
\text { dislocation } \\
\text { loops } \\
\text { dominate }\end{array}$} \\
\hline & & 100 & 399 & $14.7 \pm 0.2$ & 1.3 & \\
\hline & & 500 & 294 & $27.2 \pm 0.5$ & 0.7 & \\
\hline & 500 & 100 & \multicolumn{4}{|c|}{ Dislocation segments } \\
\hline \multirow{5}{*}{ HCM12A } & \multirow{3}{*}{400} & 30 & 81 & $13.5 \pm 0.3$ & 0.5 & \multirow{3}{*}{$\begin{array}{l}100>\text { type } \\
\text { dislocation } \\
\text { loops } \\
\text { dominate }\end{array}$} \\
\hline & & 100 & 113 & $12.7 \pm 0.3$ & 1.5 & \\
\hline & & 500 & 205 & $21.6 \pm 0.6$ & 1.4 & \\
\hline & \multirow{2}{*}{500} & 100 & \multicolumn{4}{|c|}{ Dislocation segments } \\
\hline & & 500 & \multicolumn{4}{|c|}{ Dislocation segments } \\
\hline \multirow{3}{*}{$\begin{array}{l}9 \mathrm{Cr} \\
\text { Model }\end{array}$} & \multirow{3}{*}{400} & 7 & 201 & $11.6 \pm 2.1$ & 1.0 & $\begin{array}{l}<100>\text { and } \\
1 / 2<111>\end{array}$ \\
\hline & & 30 & 178 & $12.9 \pm 2.3$ & 2.5 & \multirow{3}{*}{$\begin{array}{l}<100>\text { type } \\
\text { dislocation } \\
\text { loops } \\
\text { dominate }\end{array}$} \\
\hline & & 500 & 165 & $14.1 \pm 3.5$ & 3.6 & \\
\hline $\begin{array}{c}12 \mathrm{Cr} \\
\text { Model }\end{array}$ & 400 & 500 & 177 & $11.2 \pm 2.2$ & 3.5 & \\
\hline \multirow[t]{4}{*}{ NF616 } & 500 & 1 & - & 8.07 & 0.08 & \multirow{3}{*}{$\begin{array}{l}\text { Clusters } \\
\text { and } \\
\text { dislocation } \\
\text { loops } \\
\end{array}$} \\
\hline & & 2 & - & 9.61 & 0.309 & \\
\hline & & 3 & - & 9.72 & 0.32 & \\
\hline & 700 & $1-3$ & \multicolumn{4}{|c|}{ Dislocation segments or networks } \\
\hline
\end{tabular}



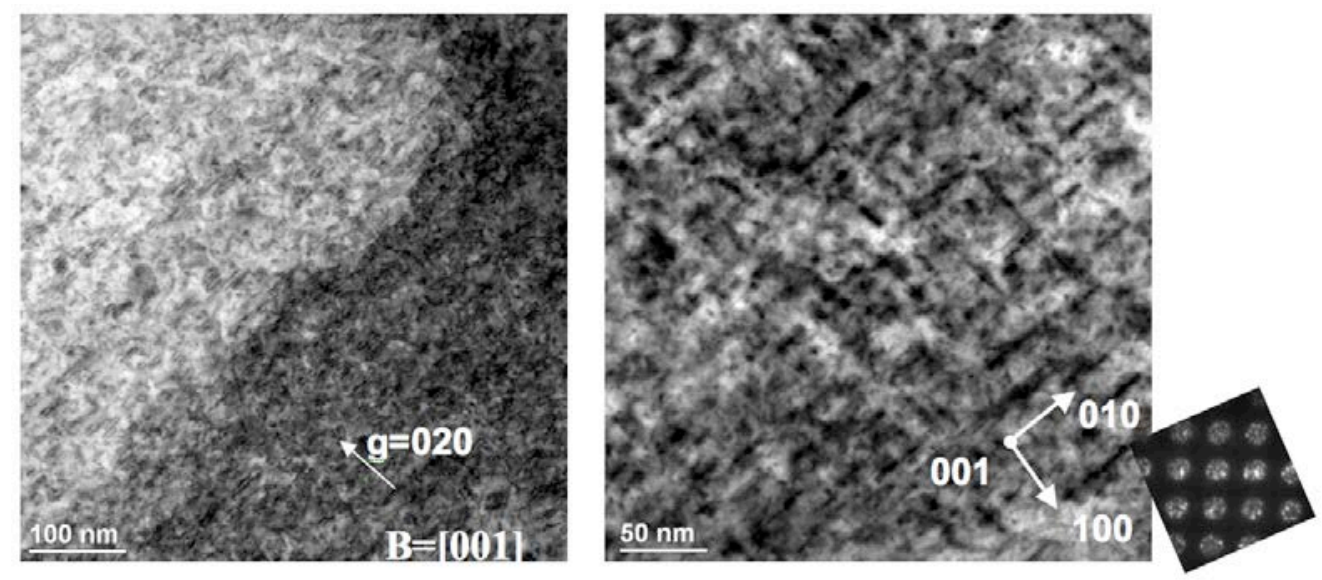

Figure 1. a) $<100>$ type of dislocation loops in T91 following irradiation to 100 dpa at $400^{\circ} \mathrm{C}$ as revealed using bright field TEM image with $b=[001]$ and $g=020$ (b) and STEM bright field image under multi-beam condition along $b=[001]$.
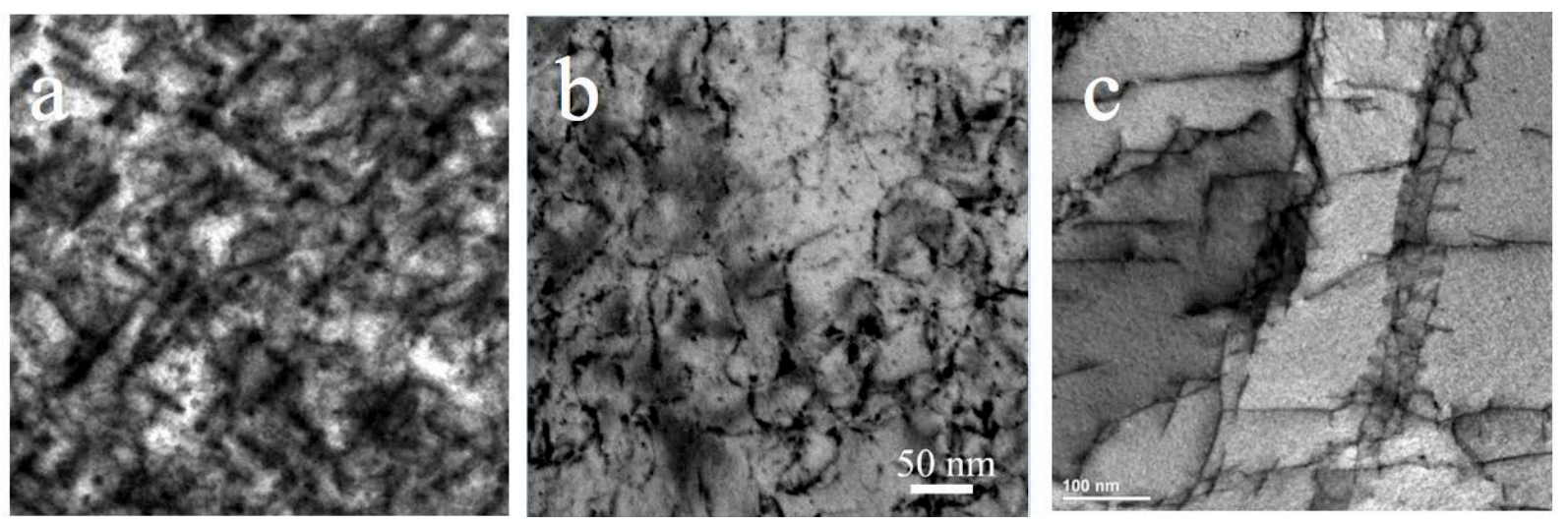

Figure 2. Dislocation loop evolution in T91 following $\mathrm{Fe}^{++}$irradiation at various doses and temperatures: (a) $400^{\circ} \mathrm{C}: 100 \mathrm{dpa}$ (b) $440^{\circ} \mathrm{C}: 30 \mathrm{dpa}$, and (c) $500^{\circ} \mathrm{C}: 100 \mathrm{dpa}$.
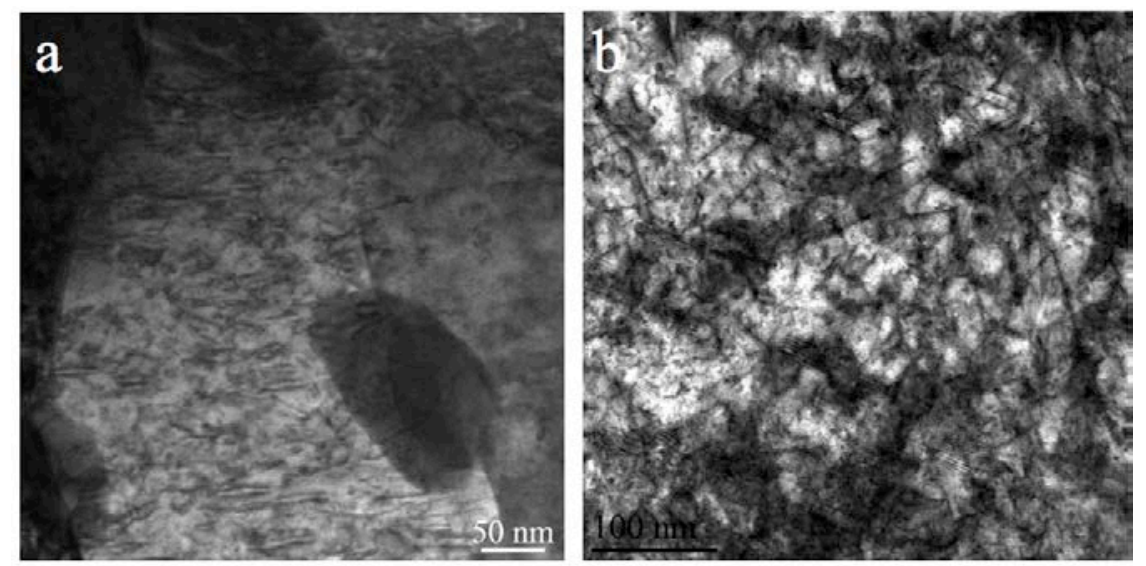

Figure 3. Dislocation microstructure in $\mathrm{HCM} 12 \mathrm{~A}$ following $\mathrm{Fe}^{++}$irradiation to 500 dpa at (a) $400^{\circ} \mathrm{C}$, and (b) $500^{\circ} \mathrm{C}$. 

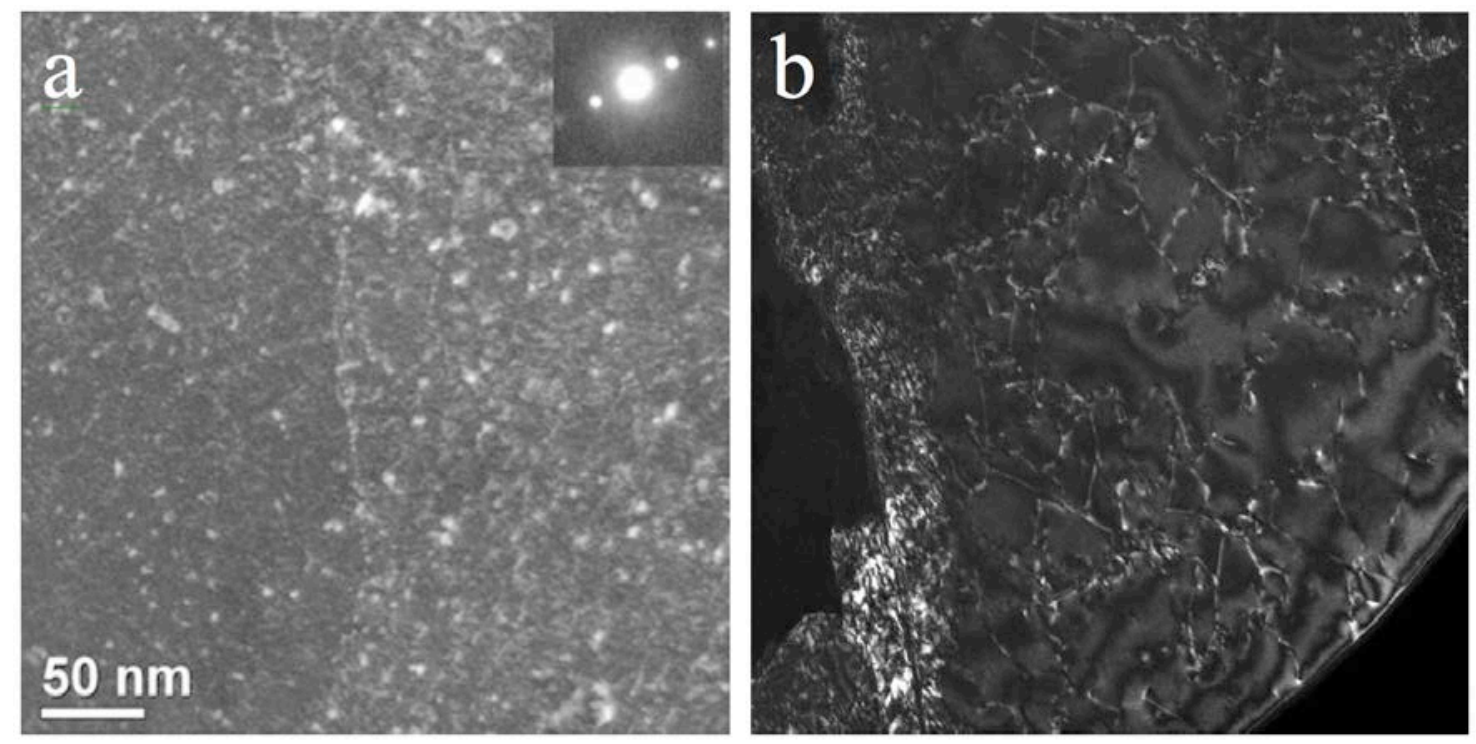

Figure 4. Irradiated microstructures of NF616 to $3 \mathrm{dpa}$ : (a) $500^{\circ} \mathrm{C}$ and (b) $700^{\circ} \mathrm{C}$.
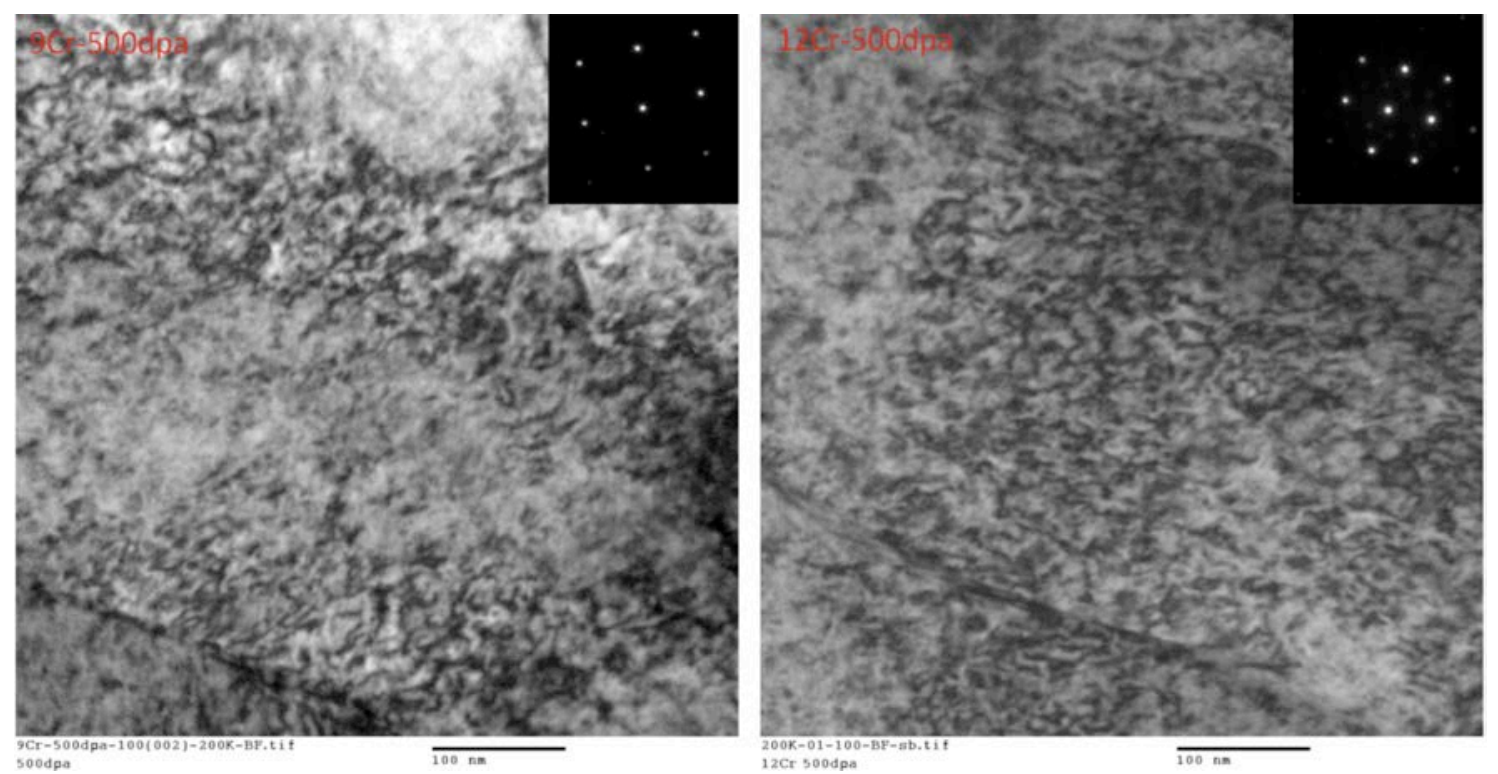

Figure 5. Dislocation microstructures of 9 and $12 \mathrm{Cr}$ model alloys irradiated at $400^{\circ} \mathrm{C}$ to $500 \mathrm{dpa}$. 

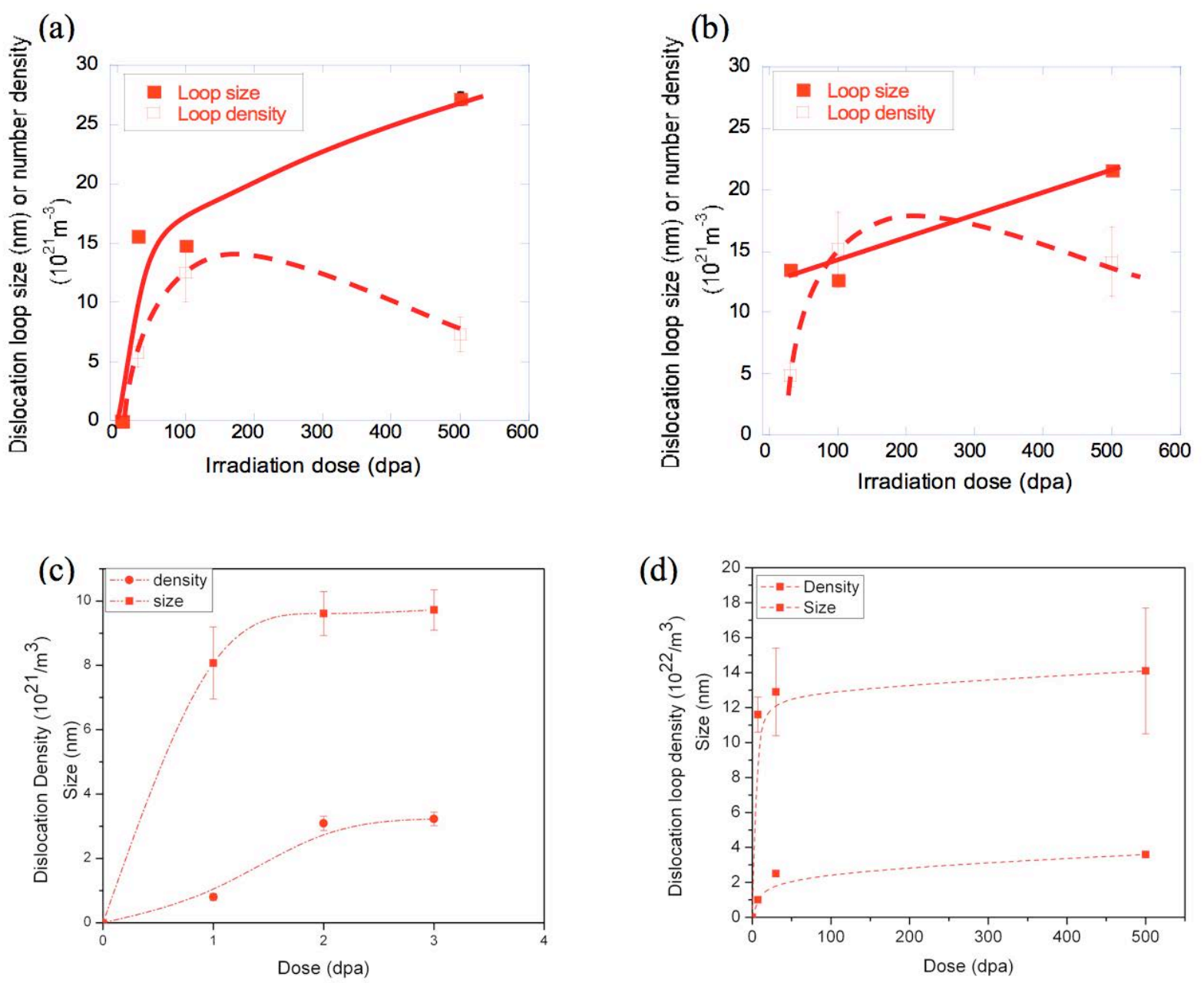

Figure 6. Dislocation evolution vs. dose in (a) $\mathrm{T} 91\left(\mathrm{Fe}^{++}\right.$irradiated at $\left.400^{\circ} \mathrm{C}\right)$, (b) $\mathrm{HCM} 12 \mathrm{~A}\left(\mathrm{Fe}^{++}\right.$ irradiated at $400^{\circ} \mathrm{C}$ ), (c) NF616 (proton irradiated at $500^{\circ} \mathrm{C}$ ) and (d) $9 \mathrm{Cr}$ model alloy $\left(\mathrm{Fe}^{++}\right.$ irradiated at $400^{\circ} \mathrm{C}$ ). 


\subsection{Radiation-Induced Precipitates}

Irradiation-induced precipitates were examined in ion irradiated F-M alloys including T91, HCM12A and HT9 using atom probe tomography (APT). 3D reconstruction and data analysis was conducted using IVAS 3.4 software from the CAMECA.

$\mathrm{Ni} / \mathrm{Si} / \mathrm{Mn}$-rich, $\mathrm{Cu}-$ rich and $\mathrm{Cr}$-rich precipitates are three commonly observed radiationinduced or radiation-enhanced precipitates in ion-irradiated F-M alloys. The type of precipitates is heavily dependent on alloy composition.

As $\mathrm{Ni}, \mathrm{Si}$ and $\mathrm{Mn}$ are the common elements in F-M alloys, Ni/Si/Mn-rich clusters/precipitates are observed in all three alloys (T91, HCM12A and HT9). The observation is consistent for both ion irradiations (both proton and self-ion irradiations) and neutron irradiations. Therefore, $\mathrm{Ni} / \mathrm{Si}$ rich precipitates are probably the most common radiation-induced precipitates in F-M alloys containing $\mathrm{Ni}$ and $\mathrm{Si}$. The Ni/Si/Mn-rich clusters/precipitates can be G-phase $\left(\mathrm{M}_{6} \mathrm{Ni}_{16} \mathrm{Si}_{7}\right)$ particles or their precursors depending on the irradiation conditions. Cu-rich precipitates only appear in HCM12A and T91 under both proton and $\mathrm{Fe}^{++}$irradiations. No apparent $\mathrm{Cu}$-rich precipitates are observed in HT9 as its bulk Cu content is only $\sim 0.04 \mathrm{wt} \%$. The volume fraction of $\mathrm{Cu}$-rich precipitates are apparently dependent on bulk $\mathrm{Cu}$ content and it is much higher in HCM12A (1.02 wt\% bulk Cu content) than in T91 ( $0.17 \mathrm{wt} \%$ bulk Cu content) under the same irradiation condition. $\mathrm{Cu}$-rich precipitates are radiation enhanced and follow a similar nucleation, growth and coarsening (NGC) pattern as those observed in RPV steels. Cr-rich precipitates are slightly complex in F-M alloys. They are $\alpha^{\prime}$-phase or its precursors in proton irradiated samples. In $\mathrm{Fe}^{++}$irradiated $\mathrm{F}-\mathrm{M}$ alloys, radiation-induced Cr-rich precipitates normally contain a few percent of carbon and in some cases they are $\eta$ carbides $\left(\mathrm{M}_{6} \mathrm{C}\right)$. More details on the three types of precipitates from the research in this project can be found in publications [1] and [2.

Figure 7 shows examples of the three types of precipitates formed in F-M alloys following $\mathrm{Fe}^{++}$ irradiation to $500 \mathrm{dpa}$ at $400^{\circ} \mathrm{C}$. The proxigrams on the right show the composition of the three precipitates as indicated by arrows in T91. Note that the composition of the $\mathrm{Ni} / \mathrm{Si} / \mathrm{Mn}$-rich precipitates is very close to the G-phase. $\mathrm{Cu}$-rich precipitates tend to form near $\mathrm{Ni} / \mathrm{Si} / \mathrm{Mn}$-rich precipitates. This phenomenon has been confirmed in both ion and neutron irradiated HCM12A.

\section{There is an incubation dose for precipitate nucleation in ion irradiated F-M alloys.} Precipitate coarsening occurred at high doses.

An incubation dose exists for $\mathrm{Ni} / \mathrm{Si} / \mathrm{Mn}$-rich precipitates for both proton and heavy ion irradiations. In proton irradiation the incubation dose appears to be greater than $1 \mathrm{dpa}$ while in $\mathrm{Fe}^{++}$irradiation, the incubation dose is $>7 \mathrm{dpa}$. The difference in incubation dose is probably due to dose rate, which is about two orders of magnitude higher for heavy ion irradiations compared to proton irradiations. As shown in Figure 8 for both T91 and HCM12A following $\mathrm{Fe}^{++}$ irradiation at $400^{\circ} \mathrm{C}$, no Ni/Si/Mn-rich clusters form at $7 \mathrm{dpa}$. Ni/Si/Mn-rich precipitates appear at $30 \mathrm{dpa}$ and there is virtually no change up to $100 \mathrm{dpa}$. Slight coarsening occurs at very high dose of 500 dpa. Quantitative analysis is shown in Figure 9. It can be seen that coarsening of the 
$\mathrm{Ni} / \mathrm{Si} / \mathrm{Mn}$-rich precipitates occurs at $500 \mathrm{dpa}$ for both HCM12A and T91. Incubation dose for $\mathrm{Cu}$-rich precipitates apparently is dependent on bulk composition. They appear at $7 \mathrm{dpa}$ for HCM12A with high $\mathrm{Cu}$ content and 30 dpa for T91 with low $\mathrm{Cu}$ content. Also the coarsening process for HCM12A occurs at a low dose of $<30$ dpa (Figure 9) while the coarsening process for T91 is not obvious even at $500 \mathrm{dpa}$. The density and Cr-rich precipitates is generally low and a clear trend of evolution with dose was not seen. The nucleation sites of $\mathrm{Cr}$-rich precipitates are independent of the other two types of precipitates.

Irradiation temperature has an appreciable effect on precipitates. Precipitates are larger and at lower density at high irradiation temperature.

The effect of irradiation temperature on precipitate size and density is very predictable with larger precipitates at lower density at higher temperature. An example of the temperature effect on the $\mathrm{Cu}$-rich precipitates following $\mathrm{Fe}^{++}$irradiation to 100 dpa in HCM12A and T91 is shown in Figure 10. Precipitates are evidently larger and at lower density at $500^{\circ} \mathrm{C}$ compared to those at $400^{\circ} \mathrm{C}$. A similar temperature effect on $\mathrm{Ni} / \mathrm{Si} / \mathrm{Mn}$-rich precipitates was also observed. The size and density of $\mathrm{Ni} / \mathrm{Si} / \mathrm{Mn}$-rich and $\mathrm{Cu}$-rich precipitates in $\mathrm{HCM} 12 \mathrm{~A}$ irradiated at $500^{\circ} \mathrm{C}$ are compared to those at $400^{\circ} \mathrm{C}$ in Figure 9. The substantial difference in size and density with temperature indicates the much lower nucleation rate at $500^{\circ} \mathrm{C}$ compared to that at $400^{\circ} \mathrm{C}$.

\section{A high volume fraction of radiation-induced carbides forms in F-M alloys after irradiation to high dose and high temperature.}

Irradiation at high temperature to high dose $\left(500^{\circ} \mathrm{C}\right.$ : $\left.500 \mathrm{dpa}\right)$ results in the formation of $\mathrm{Cr}_{6} \mathrm{C}$ as shown in Figure 11 from the APT atom maps, and from TEM/EDS and diffraction patterns in HCM12A. Formation of $\mathrm{Cr}_{6} \mathrm{C}$ is probably due to the dissolution of pre-existing $\mathrm{Cr}_{23} \mathrm{C}_{6}$ as suggested by Maziasz [3]. At this extreme condition, partial dissolution of $\mathrm{Cu}$-rich precipitates may occur leading to the smaller volume fraction of $\mathrm{Cu}$-rich precipitates at $500 \mathrm{dpa}$ than that at 100 dpa [2]. Further coarsening of $\mathrm{Ni} / \mathrm{Si} / \mathrm{Mn}$-rich precipitates at 500 dpa leads to a very low number density that may be missed by the limited examined area. Figure 11 shows large $\mathrm{Ni} / \mathrm{Si} / \mathrm{Mn}$-rich precipitates attached to a carbide in $\mathrm{HT} 9$ irradiated at $500^{\circ} \mathrm{C}: 500 \mathrm{dpa}$. Significant segregation of Si to the carbide-matrix interface is also observed. 

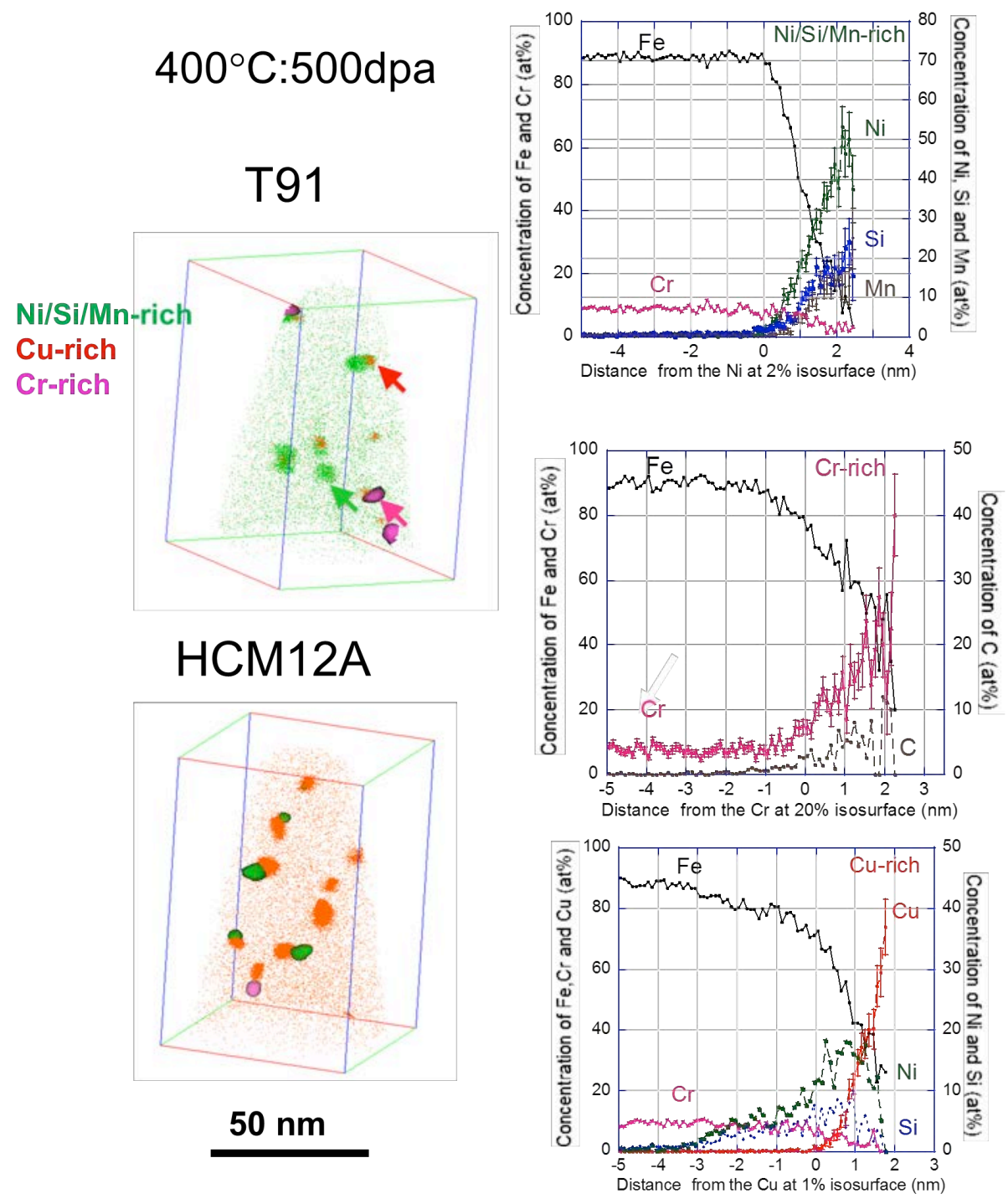

Figure 7. Formation of $\mathrm{Ni} / \mathrm{Si} / \mathrm{Mn}$-rich, $\mathrm{Cu}$-rich and $\mathrm{Cr}$-rich precipitates in T91 and HCM12A following $\mathrm{Fe}^{++}$irradiation to $500 \mathrm{dpa}$ at $400^{\circ} \mathrm{C}$. Graphs on the right are proxigrams of the three precipitates in T91 indicated by arrows in the left. 


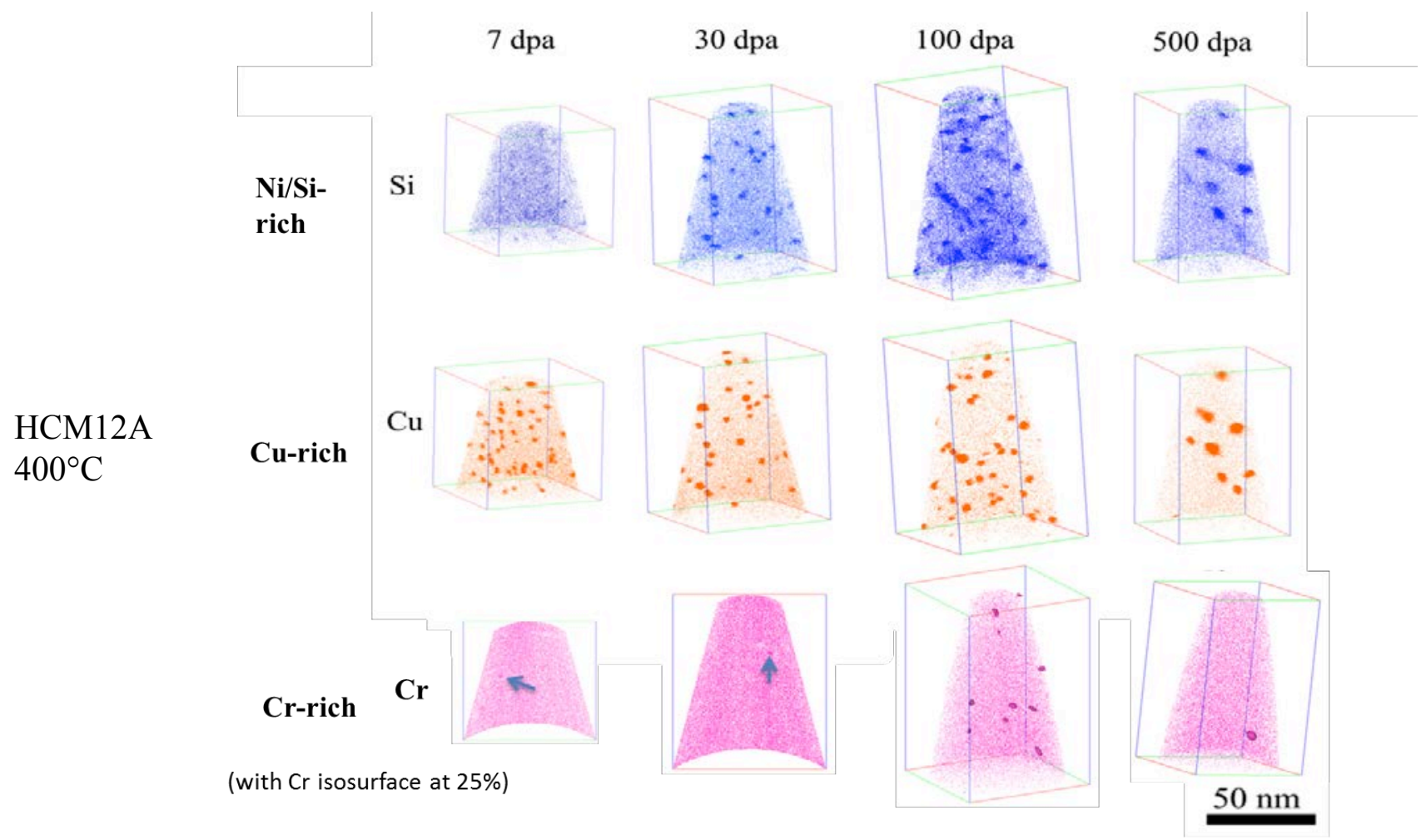

T91

$400^{\circ} \mathrm{C}$
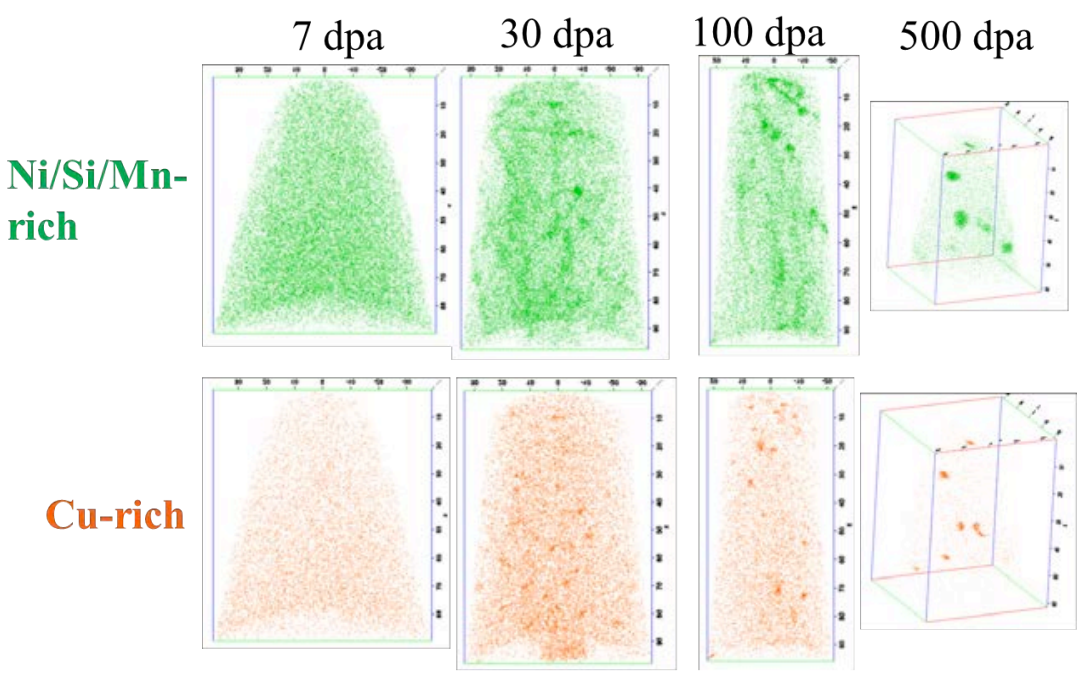

Figure 8. Evolution of $\mathrm{Ni} / \mathrm{Si} / \mathrm{Mn}$-rich and $\mathrm{Cu}$-rich precipitates with dose in HCM12A and T91 following $\mathrm{Fe}^{++}$irradiation at $400^{\circ} \mathrm{C}$. The $\mathrm{Cr}$-rich precipitates are shown using $\mathrm{Cr}$ isosurface at 25 at $\%$ in $\mathrm{HCM} 12 \mathrm{~A}$. 

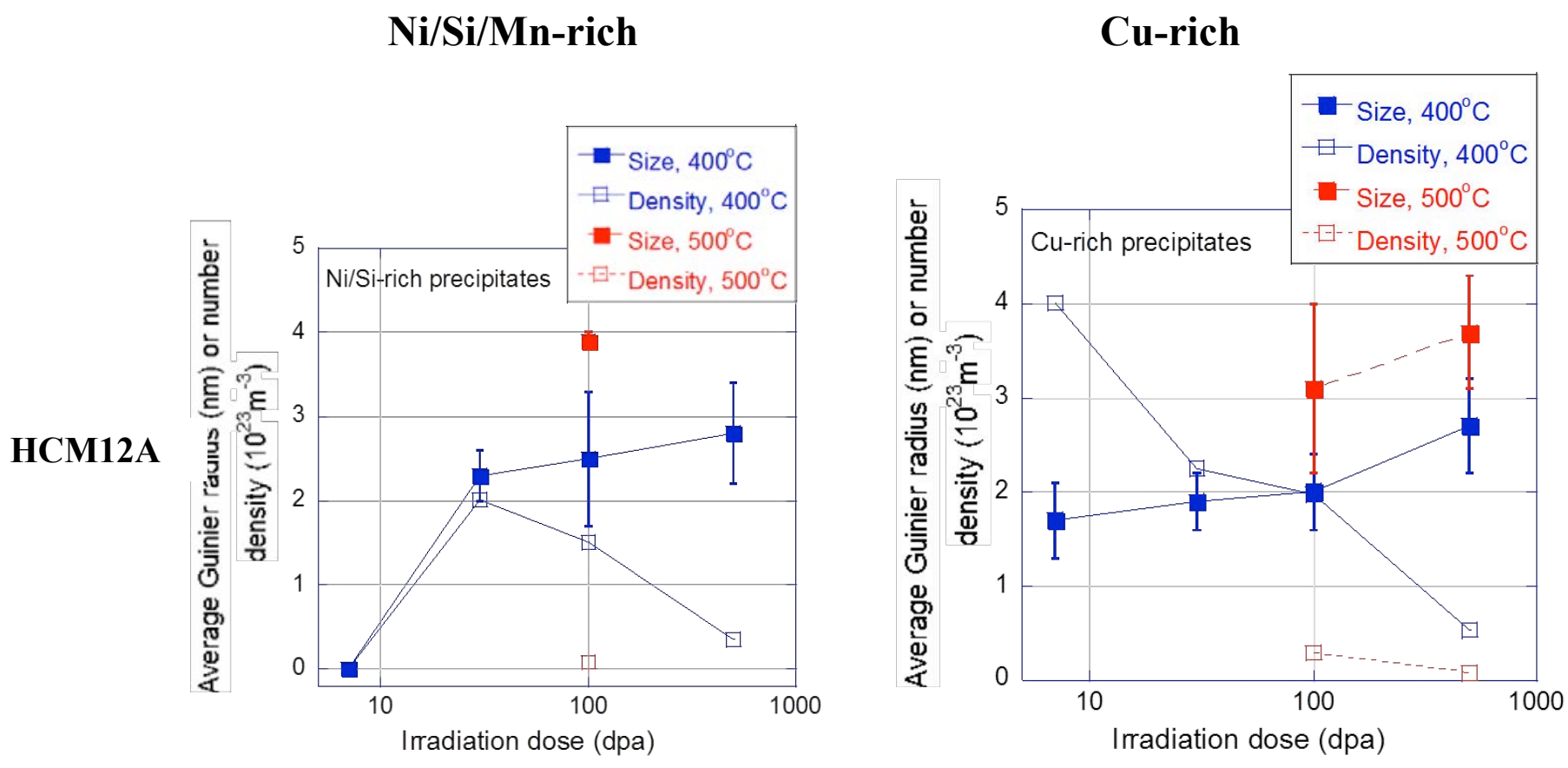

T91
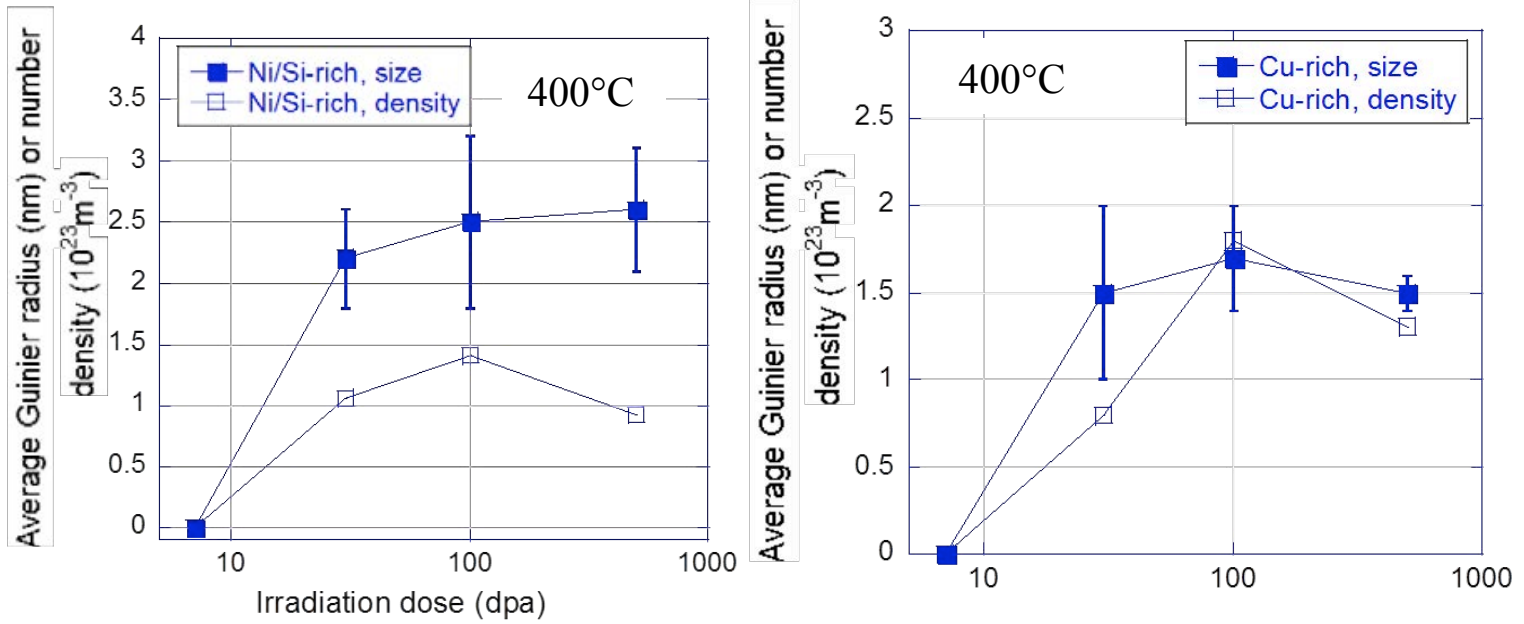

Figure 9. Evolution of size (average Guinier radius) and number density of Ni/Si/Mn-rich and $\mathrm{Cu}$-rich precipitates with dose in HCM12A and T91. 


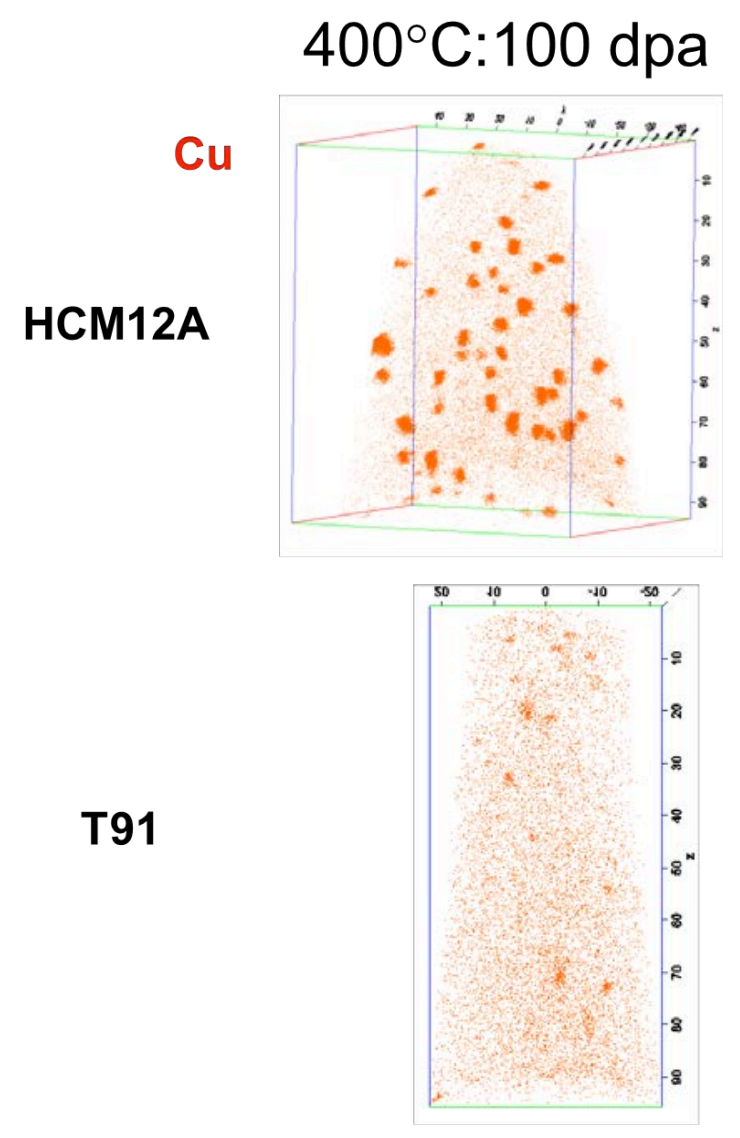

\section{$500^{\circ} \mathrm{C}: 100 \mathrm{dpa}$}
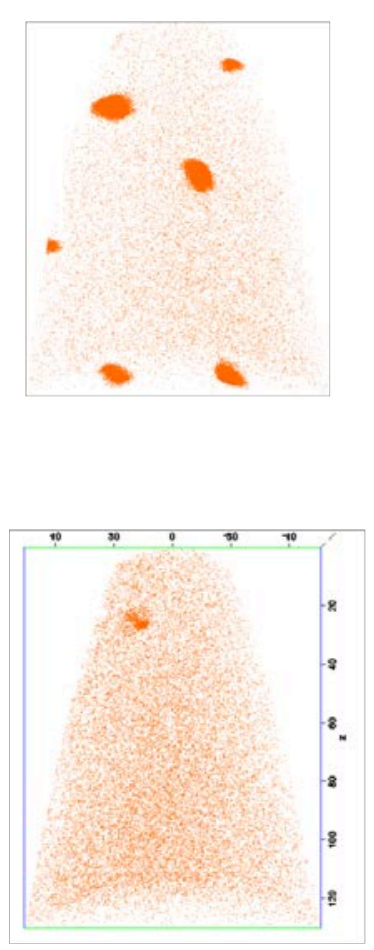

$50 \mathrm{~nm}$

Figure 10. Temperature effect on Cu-rich precipitates in HCM12A and T91 following Fe ${ }^{++}$ irradiation to $100 \mathrm{dpa}$. 

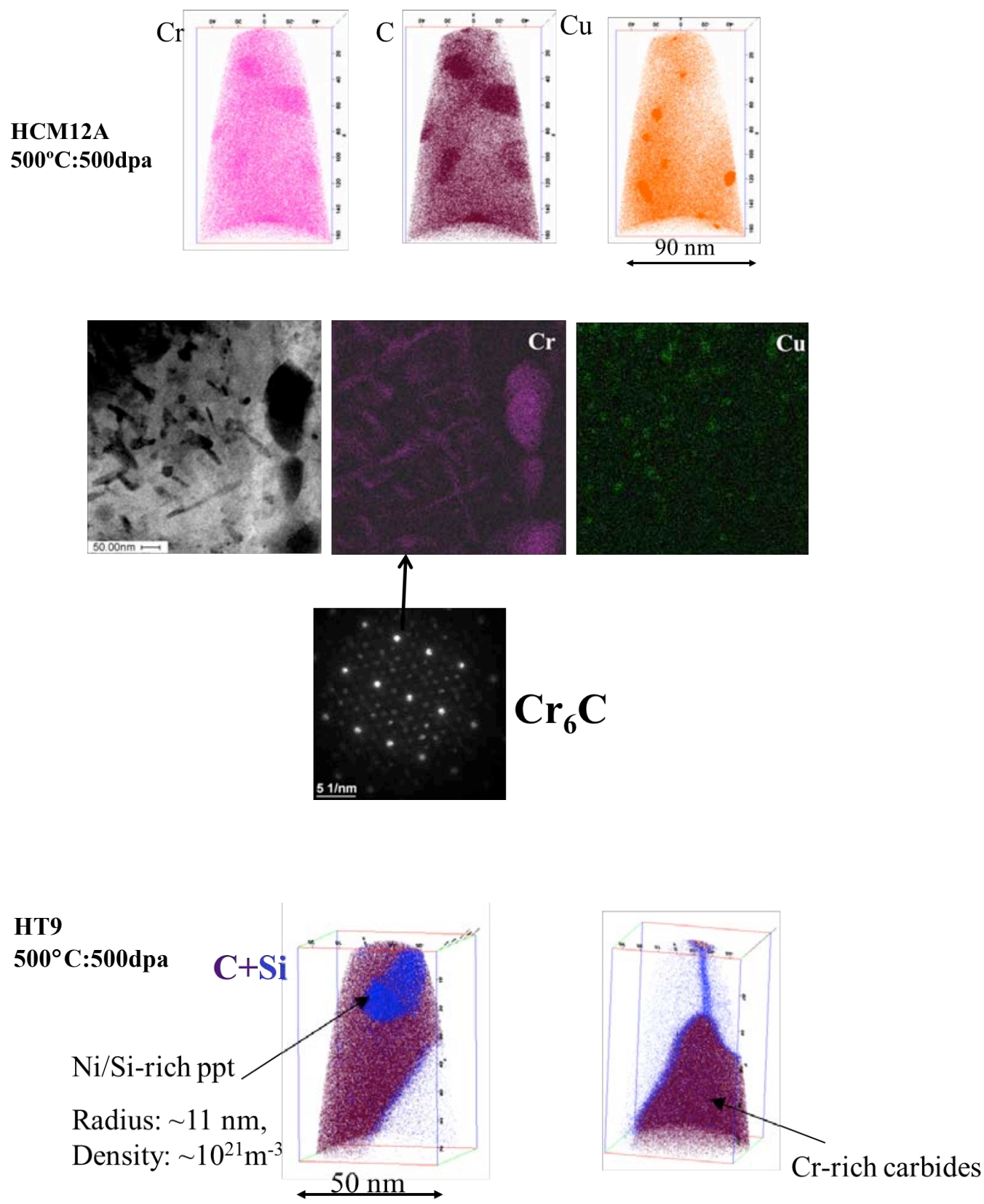

Figure 11. Formation of $\mathrm{M}_{6} \mathrm{C}$ carbides in $\mathrm{HCM} 12 \mathrm{~A}$ and large Ni/Si/Mn-rich precipitates (Gphase) in $\mathrm{HT} 9$ following $\mathrm{Fe}^{++}$irradiation to $500 \mathrm{dpa}$ at $500^{\circ} \mathrm{C}$. 


\subsection{Nanoclusters in ODS alloys}

\section{Heavy ion irradiation at $300^{\circ} \mathrm{C}$ leads to a substantial decrease in size and number density of nanoclusters in 14YWT. There are minimal changes in size and number density of nanoclusters in $14 \mathrm{YWT}$ irradiated at $450^{\circ} \mathrm{C}$ to $600^{\circ} \mathrm{C}$ compared to the unirradiated case.}

The 14YWT oxide dispersion strengthened (ODS) ferritic steel (nominal composition: Fe$14 \mathrm{at} \% \mathrm{Cr}-3 \mathrm{at} \% \mathrm{~W}-0.4 \mathrm{at} \% \mathrm{Ti}-0.25 \mathrm{at} \% \mathrm{Y}_{2} \mathrm{O}_{3}$ ) was provided by Oak Ridge National Laboratory (ORNL). Ion irradiations were conducted using Pelletron tandem accelerator at the Environmental and Molecular Science Laboratory (EMSL) at Pacific Northwest National Laboratory (PNNL) using $5 \mathrm{MeV} \mathrm{Ni}^{2+}$ ions at $-75^{\circ} \mathrm{C}, 100^{\circ} \mathrm{C}, 300^{\circ} \mathrm{C}, 450^{\circ} \mathrm{C}, 600^{\circ} \mathrm{C}$, and $700^{\circ} \mathrm{C}$ to damage levels of $100 \mathrm{dpa}$ in the investigating area. 3-D atoms distribution maps of elements chromium, titanium, yttrium, oxygen in the unirradiated 14YWT ODS steel are shown in Figure 12. Nanoclsuters are associated by the regions enriched with $\mathrm{O}$, Ti and $\mathrm{Y}$ atoms.

The atom maps of elements of 14YWT collected by APT showed that the nanoclusters were largely eliminated during irradiation at $-75^{\circ} \mathrm{C}$ and $100^{\circ} \mathrm{C}$, and very few nanoclusters were observed to remain in the APT 3D map for the samples irradiated at $300^{\circ} \mathrm{C}$ to 100 dpa as shown in

Figure 12(b), (c) and (d). The nanoclusters that remaining were smaller than those in the unirradiated sample, indicating that $\mathrm{Ti}, \mathrm{Y}$ and $\mathrm{O}$ from the nanoclusters had a tendency to dissolve under these irradiation conditions. In contrast, large number densities of nanoclusters were observed in samples irradiated to the same damage levels at $450^{\circ} \mathrm{C}, 600^{\circ} \mathrm{C}$, and $700^{\circ} \mathrm{C}$ samples. For these samples, zones of $\mathrm{Ti}, \mathrm{Y}$ and $\mathrm{O}$ enrichment were similar to the unirradiated samples, revealing a stable nanoclusters population, as shown in

Figure 12(e), (f) and (g).

The nanocluster size distribution at different irradiation temperatures are shown in

Figure 13. The average Guinier radius, $\left\langle\mathrm{R}_{\mathrm{g}}>\right.$, and number density, $\mathrm{N}_{\mathrm{v}}$, are also included. The peak of the nanocluster size distribution for the samples was about $0.8 \mathrm{~nm}$. The average Guinier radii of the unirradiated sample and samples irradiated at $300^{\circ} \mathrm{C}, 450^{\circ} \mathrm{C}, 600^{\circ} \mathrm{C}$, and $700^{\circ} \mathrm{C}$ samples were $1.1 \pm 0.5,0.8 \pm 0.2,1.2 \pm 0.6,1.1 \pm 0.5 \mathrm{~nm}$ and $1.1 \pm 0.5$, respectively, and corresponding number densities were $12 \times 10^{23}, 3.7 \times 10^{23}, 9.1 \times 10^{23}, 7.2 \times 10^{23}$ and $6.0 \times 10^{23} \mathrm{~m}^{-3}$. These values show that after irradiation at $300^{\circ} \mathrm{C}$ the average nanocluster size decreased by about $25 \%$ and the number density decreased by $70 \%$. Less dramatic changes were observed for samples irradiated at $450^{\circ} \mathrm{C}, 600^{\circ} \mathrm{C}$ and $700^{\circ} \mathrm{C}$ samples.

Irradiation resulted in a variation in the nanocluster composition, as indicated in Table 2 . The composition of the nanoclusters and matrix of 14YWT steel determined using the maximum separation method [4] in this study are also summarized in Table 2. Here the $\mathrm{Ti} / \mathrm{Y}$ ratio aprroaches $\approx 4$ in the nanoclusters of $450^{\circ} \mathrm{C}$ and $600^{\circ} \mathrm{C}$ irradiated samples that were similar to the unirradiated samples, but this ratio was 1.5 in the $300^{\circ} \mathrm{C}$ samples and 2.0 in the $700^{\circ} \mathrm{C}$ samples. That may indicates that the $\mathrm{Ti} / \mathrm{Y}$ ratio was controlled by the size of naonclusters and the irradiation temperature. The metal-to-oxygen $([\mathrm{Ti}+\mathrm{Y}]: \mathrm{O})$ ratio was approximately $1: 1$ in all samples. 
Irradiation at $-50^{\circ} \mathrm{C}$ and $200^{\circ} \mathrm{C}$ led to an apparent decrease in the average size and the number density of nanocusters in the $9 \mathrm{Cr}$-ODS. The change in size and density was much less for samples irradiated at $600^{\circ} \mathrm{C}$.

The 9Cr-ODS ferritic steels were provided by KOBELCO research institute, INC, whose chemical composition is shown in Table 3. Ion irradiation were conducted by Pelletron ${ }^{\circledR} \operatorname{tandem}$ accelerator at the Environmental and Molecular science laboratory at Pacific Northwest National Laboratory (PNNL) using $10 \mathrm{MeV} \mathrm{Pt}^{3+}$ ions at $-50^{\circ} \mathrm{C} / 100 \mathrm{dpa}, 200^{\circ} \mathrm{C} / 100 \mathrm{dpa}, 600^{\circ} \mathrm{C} / 100 \mathrm{dpa}$.

Figure 14 shows the atom maps of elements collected by APT after $\mathrm{Pt}^{3}+$ irradiation at $-50^{\circ} \mathrm{C}$, $200^{\circ} \mathrm{C}$ and $600^{\circ} \mathrm{C}$. Very few nanoclusters were observed to be present in the APT 3D maps for the samples irradiated at $200^{\circ} \mathrm{C}$ and $100 \mathrm{dpa}$ as shown in the Figure $14 \mathrm{c}$. The nanoclusters were nearly eliminated in the $-50^{\circ} \mathrm{C}: 100 \mathrm{dpa}$ sample suggesting that the nanocluster is not stable during irradiation at very low temperature. In contrast, Figure $14 \mathrm{~d}$ showed a large number densities of nanoclusters in samples irradiated at $600^{\circ} \mathrm{C}$, even at a damage level of $200 \mathrm{dpa}$. The nanocluster size distributions at each condition are shown in Figure 15. The average Guinier radius, $\left\langle\mathrm{R}_{\mathrm{g}}>\right.$, and number density, $\mathrm{N}_{\mathrm{v}}$, were also included. The peak of the nanocluster size distribution for the samples was about $0.8 \mathrm{~nm}$ in the $-50^{\circ} \mathrm{C}$ and $200^{\circ} \mathrm{C}$ samples, and about $1.6 \mathrm{~nm}$ and $1.2 \mathrm{~nm}$ in the unirradiated and $600^{\circ} \mathrm{C}$ irradiated samples. The average Guinier radii of the unirradiated sample and those irradiated at $-50{ }^{\circ} \mathrm{C}, 200^{\circ} \mathrm{C}$ up to $100 \mathrm{dpa}$ and $600^{\circ} \mathrm{C}$ samples with damage level up to 200dpa were $1.4 \pm 0.5 \mathrm{~nm}, 0.8 \pm 0.1 \mathrm{~nm}, 0.9 \pm 0.5 \mathrm{~nm}, 1.3 \pm 0.5 \mathrm{~nm}$, respectively, and corresponding number densities were $9.8 \times 10^{23}, 0.6 \times 10^{23}, 6.1 \times 10^{23}$ and $9.8 \times 10^{23} \mathrm{~m}^{-3}$. These values show that after irradiation at $-50^{\circ} \mathrm{C}$ the average nanocluster size was reduced by about $45 \%$ and the number density decreased by $95 \%$. In the $200^{\circ} \mathrm{C}$ samples, average nanocluster size was reduced by about $35 \%$ and the number density decreased by $50 \%$. Less change in size and density was observed for samples irradiated at $600^{\circ} \mathrm{C}$.

The composition of the nanoclusters and matrix of 9Cr-ODS steel in this study are summarized in Table 4. Here the $\mathrm{Ti} / \mathrm{Y}$ ratio aprroaches $\approx 4.5$ in the nanoclusters of $600^{\circ} \mathrm{C}$ irradiated samples that were similar to the unirradiated samples, but this ratio was 2 in the $200^{\circ} \mathrm{C}$ samples. The value of the metal-to-oxygen $([\mathrm{Ti}+\mathrm{Y}]: \mathrm{O})$ ratio was similar in all of the samples .

Stability of nanoclusters in ODS steels during irradiation is a complex phenomenon that can be affected by various intrinsic and extrinsic factors such as alloy composition and irradiation conditions (temperature, damage rate, etc) [5]. During irradiation, the nanoclusters could grow through diffusion of solute atoms from the matrix and surrounding nanoclusters or may shrink due to radiation-induced recoils or diffusion to other defect sinks (point defects, dislocation, and interface). In general, if the nanocluster is stable in the ODS steels during irradiation, the balance should be maintained -----the number of the outputting atoms is equal to the inputting atoms. Although heavy ion beam into matrix can change local chemistries and the associated local diffusion rates, radiation-enhanced diffusion by the increase of point defects has to be taken into account, which is in agreement with the existence of an effect of temperature. 


\section{A slight coarsening of nanoclusters in the 9Cr-ODS was observed as a result of proton irradiation at $400^{\circ} \mathrm{C}$ to 3.7 dpa.}

The 9Cr-ODS ferritic steels were provided by the Japan Atomic Energy Agency, whose chemical composition is shown in Table 5. Proton irradiation was conducted with a 1.7 MV Tandetron accelerator at the MIBL (Michigan Ion Beam Laboratory) using $2 \mathrm{MeV}$ protons at $400^{\circ} \mathrm{C}$ to a dose of 3.7 dpa.

Figure 16 shows atom maps for 9Cr-ODS before and after proton irradiation. After irradiation, the number density of the nanoclusters is up to $1.5 \times 10^{23} \mathrm{n} / \mathrm{m}^{3}$ with the average Guinier radii about $2.2 \pm 1.0 \mathrm{~nm}$, as shown in Table 6 . The change of number density and size of nanoclusters is less than the uncertainty of the larger nanoclusters and is not likely a significant change. The value of $(\mathrm{Ti}+\mathrm{Y}): \mathrm{O}$ ratio does not change after irradiation. However, The Ti:Y ratio decreased from 3.0 to 1.5 and the concentration of $\mathrm{Cr}$ increased from $4 \%$ to $8 \%$ after irradiation, indicating that the segregation of $\mathrm{Cr}$ occurs in the nanoclusters during irradiation.

Table 2. Compositions (at. \% ) of the matrix and nanoclusters of 14YWT irradiated under various conditions as determined by atomic probe tomography (APT).

\begin{tabular}{|l|l|l|l|l|l|}
\hline Elements & Unirradiated & \multicolumn{1}{|c|}{$300^{\circ} \mathrm{C}$} & \multicolumn{1}{c|}{$450^{\circ} \mathrm{C}$} & \multicolumn{1}{c|}{$600^{\circ} \mathrm{C}$} & $700^{\circ} \mathrm{C}$ \\
\hline Matrix & 82.8 & 86.76 & 83.61 & 83.64 & 83.40 \\
\hline $\mathrm{Fe}$ & 15.2 & 11.78 & 14.39 & 15.06 & 15.10 \\
\hline $\mathrm{Cr}$ & 0.4 & 0.67 & 0.46 & 0.52 & 0.58 \\
\hline $\mathrm{W}$ & 0.4 & 0.16 & 0.38 & 0.20 & 0.39 \\
\hline $\mathrm{O}$ & 0.19 & 0.07 & 0.18 & 0.11 & 0.13 \\
\hline $\mathrm{Ti}$ & 0.08 & 0.04 & 0.07 & 0.05 & 0.07 \\
\hline $\mathrm{Y}$ & $55.09 \pm 8.29$ & $57.98 \pm 15.15$ & $51.45 \pm 8.27$ & $56.85 \pm 7.14$ & $56.34 \pm 7.74$ \\
\hline Nanocluster| & $20.21 \pm 1.65$ & $12.29 \pm 3.1$ & $21.94 \pm 1.27$ & $20.77 \pm 1.71$ & $20.42 \pm 1.68$ \\
\hline $\mathrm{Fe}$ & $0.30 \pm 0.06$ & $0.12 \pm 0.08$ & $0.27 \pm 0.04$ & $0.47 \pm 0.08$ & $0.52 \pm 0.05$ \\
\hline $\mathrm{Cr}$ & $10.08 \pm 4.11$ & $10.65 \pm 6.21$ & $11.58 \pm 4.24$ & $9.38 \pm 3.74$ & $9.89 \pm 3.89$ \\
\hline $\mathrm{W}$ & $8.34 \pm 3.98$ & $8.21 \pm 5.71$ & $8.68 \pm 3.8$ & $7.75 \pm 3.6$ & $7.65 \pm 3.63$ \\
\hline $\mathrm{O}$ & $2.03 \pm 0.97$ & $5.36 \pm 3.79$ & $2.04 \pm 0.92$ & $2.10 \pm 0.95$ & $4.05 \pm 2.02$ \\
\hline $\mathrm{Ti}$ & $\approx 4$ & $\approx 1.5$ & $\approx 4$ & $\approx 4$ & $\approx 2$ \\
\hline $\mathrm{Y}$ & $\approx 1$ & $\approx 1$ & $\approx 1$ & $\approx 1$ & $\approx 1$ \\
\hline $\mathrm{Ti}: \mathrm{Y}$ & & & & \\
\hline$[\mathrm{Ti}+\mathrm{Y}]: \mathrm{O})$ & $\approx 1$ & & & \\
\hline
\end{tabular}

Table 3. Chemical composition of 9Cr-ODS Steel provided by KOBELCO research institute, Inc.

\begin{tabular}{|l|l|l|l|l|l|l|l|l|l|l|l|l|l|}
\hline \multicolumn{2}{|l|}{ Chemical composition (at.\%) } \\
\hline $\mathrm{C}$ & $\mathrm{Si}$ & $\mathrm{Mn}$ & $\mathrm{P}$ & $\mathrm{S}$ & $\mathrm{Ni}$ & $\mathrm{Cr}$ & $\mathrm{W}$ & $\mathrm{Ti}$ & $\mathrm{Y}$ & $\mathrm{O}$ & $\mathrm{N}$ & $\mathrm{Ar}$ & $\mathrm{Fe}$ \\
\hline 0.15 & 0.03 & 0.02 & $<0.005$ & 0.003 & 0.01 & 9.2 & 1.99 & 0.32 & 0.28 & 0.15 & 0.027 & 0.004 & Bal. \\
\hline
\end{tabular}


Table 4. Compositions (at. \% ) of the matrix and nanoclusters of 9Cr-ODS steels irradiated under various conditions as determined by atomic probe tomography (APT).

\begin{tabular}{|c|c|c|c|c|}
\hline Elements & Unirradiated & $-50^{\circ} \mathrm{C}$ & $200^{\circ} \mathrm{C}$ & $600^{\circ} \mathrm{C}$ \\
\hline \multicolumn{5}{|l|}{ Matrix } \\
\hline $\mathrm{Fe}$ & 87.89 & 88.22 & 88.06 & 88.50 \\
\hline $\mathrm{Cr}$ & 10.00 & 9.74 & 10.10 & 9.79 \\
\hline $\mathrm{W}$ & 0.25 & 0.37 & 0.27 & 0.30 \\
\hline $\mathrm{O}$ & 1.20 & 0.73 & 0.89 & 1.02 \\
\hline $\mathrm{Ti}$ & 0.36 & 0.52 & 0.31 & 0.24 \\
\hline $\mathrm{Y}$ & 0.07 & 0.11 & 0.09 & 0.04 \\
\hline \multicolumn{5}{|l|}{ Nanoclusters } \\
\hline $\mathrm{Fe}$ & 30.74 & & 29.74 & 30.19 \\
\hline $\mathrm{Cr}$ & 6.01 & & 3.71 & 6.59 \\
\hline $\mathrm{W}$ & 0.10 & & 0.23 & 0.12 \\
\hline $\mathrm{O}$ & 24.56 & & 22.60 & 25.55 \\
\hline $\mathrm{Ti}$ & 27.64 & & 21.64 & 27.18 \\
\hline $\mathrm{Y}$ & 6.24 & & 12.53 & 5.9 \\
\hline Ti:Y & $\approx 4.3$ & & $\approx 2$ & $\approx 4.5$ \\
\hline$[\mathrm{Ti}+\mathrm{Y}]: \mathrm{O})$ & $\approx 1.3$ & & $\approx 1.5$ & $\approx 1.2$ \\
\hline
\end{tabular}

Table 5. Chemical composition (wt.\%) of 9Cr-ODS Steel provided by the Japan Atomic Energy Agency

\begin{tabular}{|l|l|l|l|l|l|l|l|l|l|l|l|l|l|}
\hline \multicolumn{1}{l|}{ Chemical composition (at.\%) } \\
\hline $\mathrm{C}$ & $\mathrm{Si}$ & $\mathrm{Mn}$ & $\mathrm{P}$ & $\mathrm{S}$ & $\mathrm{Ni}$ & $\mathrm{Cr}$ & $\mathrm{W}$ & $\mathrm{Ti}$ & $\mathrm{Y}$ & $\mathrm{O}$ & $\mathrm{N}$ & $\mathrm{Ar}$ & $\mathrm{Fe}$ \\
\hline & & & & & & & & & & & & & \\
0.14 & 0.048 & $<0.05$ & $<0.02$ & 0.004 & 0.06 & 8.67 & 1.96 & 0.23 & 0.27 & 0.14 & 0.017 & 0.004 & Bal. \\
\hline
\end{tabular}

Table 6. The size and composition (at.\%) of the titanium-, oxygen- and yttrium-enriched nanoclusters with a size less than $5 \mathrm{~nm}$ in diameter as estimated by APT from the maximum separation method with $\mathrm{d}_{\max }=0.66 \mathrm{~nm}, \mathrm{n}_{\min }=8$ atoms.

\begin{tabular}{|c|c|c|c|c|c|c|}
\hline & \multicolumn{3}{|c|}{ Unirradiated specimen } & \multicolumn{3}{|c|}{ Irradiated specimen } \\
\hline & Matrix & \multicolumn{2}{|c|}{ Nanoclusters } & Matrix & \multicolumn{2}{|c|}{ Nanoclusters } \\
\hline $\mathrm{Y}$ & $0.10 \pm 0.01$ & \multicolumn{2}{|l|}{$8.76 \pm 0.23$} & $0.17 \pm 0.01$ & \multicolumn{2}{|l|}{$11.3 \pm 0.19$} \\
\hline $\mathrm{Ti}$ & $0.19 \pm 0.01$ & \multicolumn{2}{|c|}{$26.31 \pm 0.34$} & $0.26 \pm 0.01$ & \multicolumn{2}{|c|}{$16.32 \pm 0.18$} \\
\hline $\mathrm{O}$ & $0.29 \pm 0.01$ & \multicolumn{2}{|c|}{$24.12 \pm 0.08$} & $0.61 \pm 0.01$ & \multicolumn{2}{|c|}{$21.95 \pm 0.12$} \\
\hline $\mathrm{Cr}$ & $8.86 \pm 0.02$ & \multicolumn{2}{|l|}{$4.34 \pm 0.03$} & $9.64 \pm 0.03$ & \multicolumn{2}{|l|}{$8.26 \pm 0.30$} \\
\hline $\mathrm{Fe}$ & $89.61 \pm 0.02$ & \multicolumn{2}{|l|}{$29.1 \pm 0.63$} & $87.44 \pm 0.03$ & \multicolumn{2}{|c|}{$34.03 \pm 0.51$} \\
\hline $\mathrm{W}$ & $0.51 \pm 0.07$ & \multicolumn{2}{|l|}{$0.45 \pm 0.09$} & $0.54 \pm 0.007$ & \multicolumn{2}{|l|}{$0.21 \pm 0.04$} \\
\hline & & $(\mathrm{Ti}+\mathrm{Y}): \mathrm{O}$ & $\mathrm{Y}: \mathrm{Ti}$ & & $(\mathrm{Ti}+\mathrm{Y}): \mathrm{O}$ & Y: Ti \\
\hline Ratio & & 1.4 & 0.33 & & 1.4 & 0.69 \\
\hline $\mathrm{R}$ & & \multicolumn{2}{|c|}{$1.86 \pm 0.99 \mathrm{~nm}$} & & \multicolumn{2}{|c|}{$2.18 \pm 0.99 \mathrm{~nm}$} \\
\hline $\mathrm{N}_{\mathrm{V}}$ & & \multicolumn{2}{|c|}{$1.66 \times 10^{23} \mathrm{n} / \mathrm{m}^{3}$} & & \multicolumn{2}{|c|}{$1.47 \times 10^{23} \mathrm{n} / \mathrm{m}^{3}$} \\
\hline
\end{tabular}



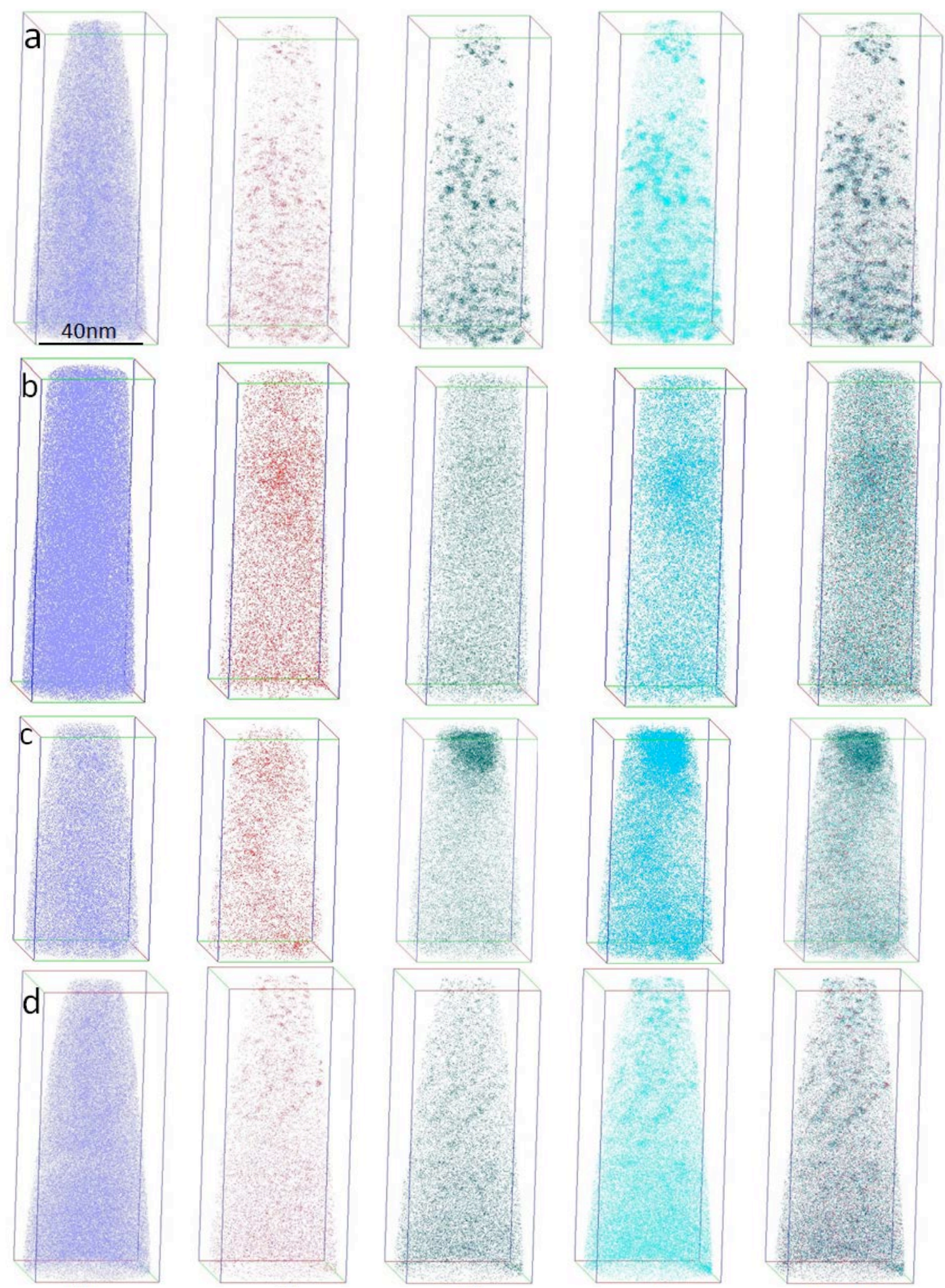

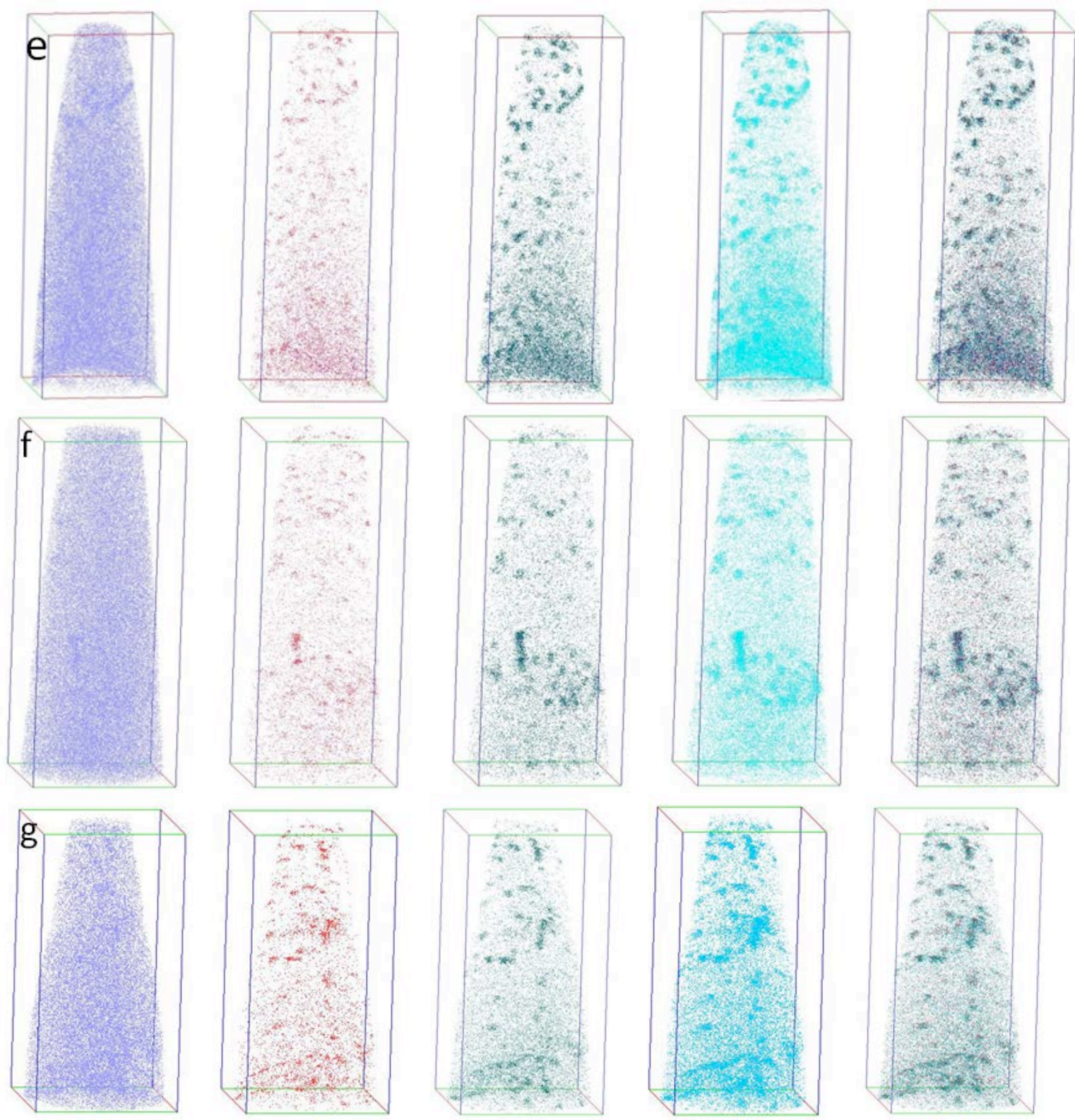

Figure 12. APT 3D reconstruction of $14 \mathrm{YWT}$ samples irradiated with $5 \mathrm{MeV}$ Ni ions to $100 \mathrm{dpa}$ at temperatures of: (a) unirradiated (b) $-75^{\circ} \mathrm{C}$ (c) $100^{\circ} \mathrm{C}$ (d) $300^{\circ} \mathrm{C}$ (e) $450^{\circ} \mathrm{C}$ (f) $600^{\circ} \mathrm{C}$, and (g) $700^{\circ} \mathrm{C}$ 


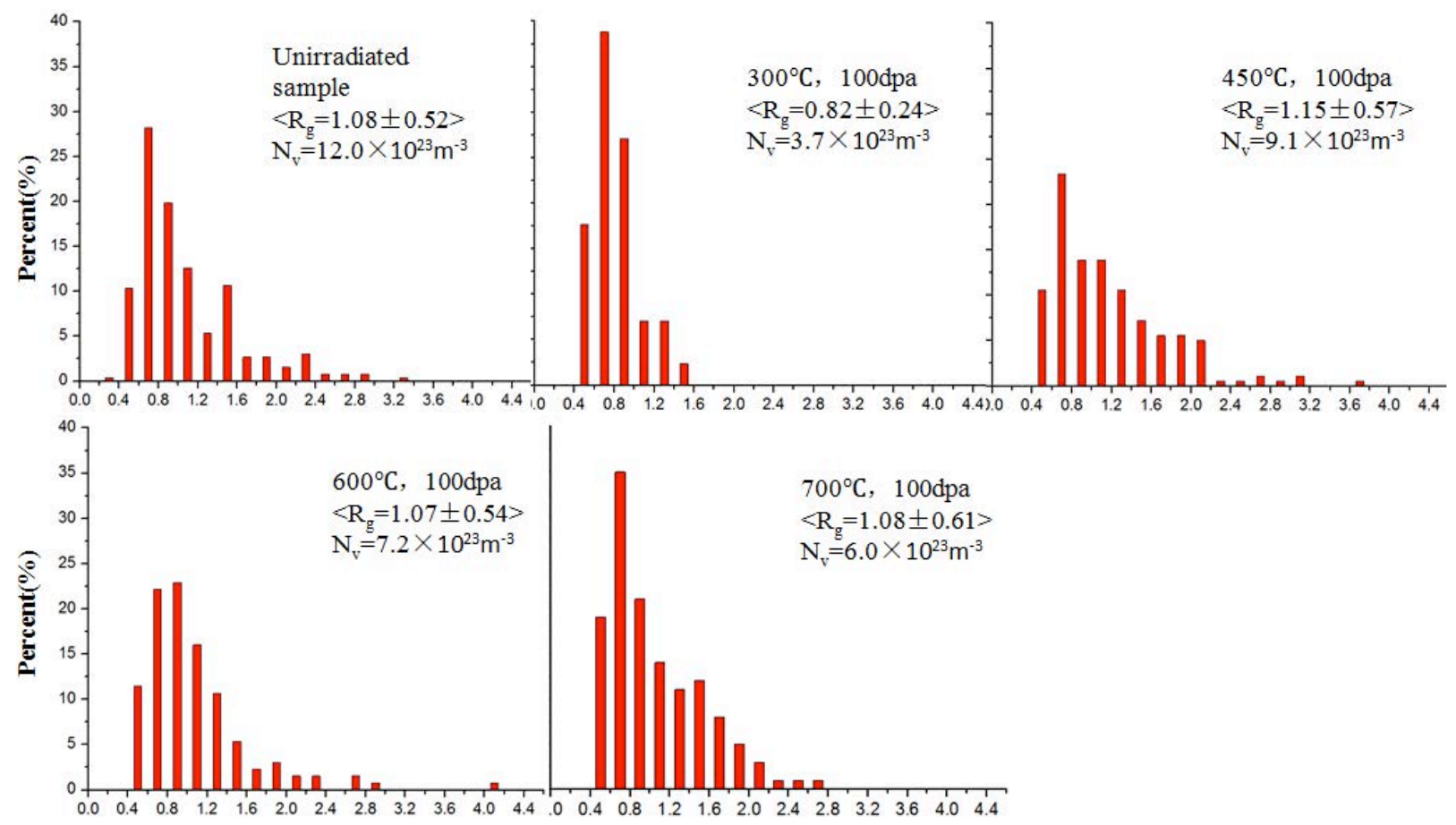

Figure 13. Nanocluster size distribution in unirradiated samples and those irradiated at $300^{\circ} \mathrm{C}$, $450^{\circ} \mathrm{C}, 600^{\circ} \mathrm{C}$, and $700^{\circ} \mathrm{C}$ up to $100 \mathrm{dpa}$ with $5 \mathrm{MeV} \mathrm{Ni}$ ions. 

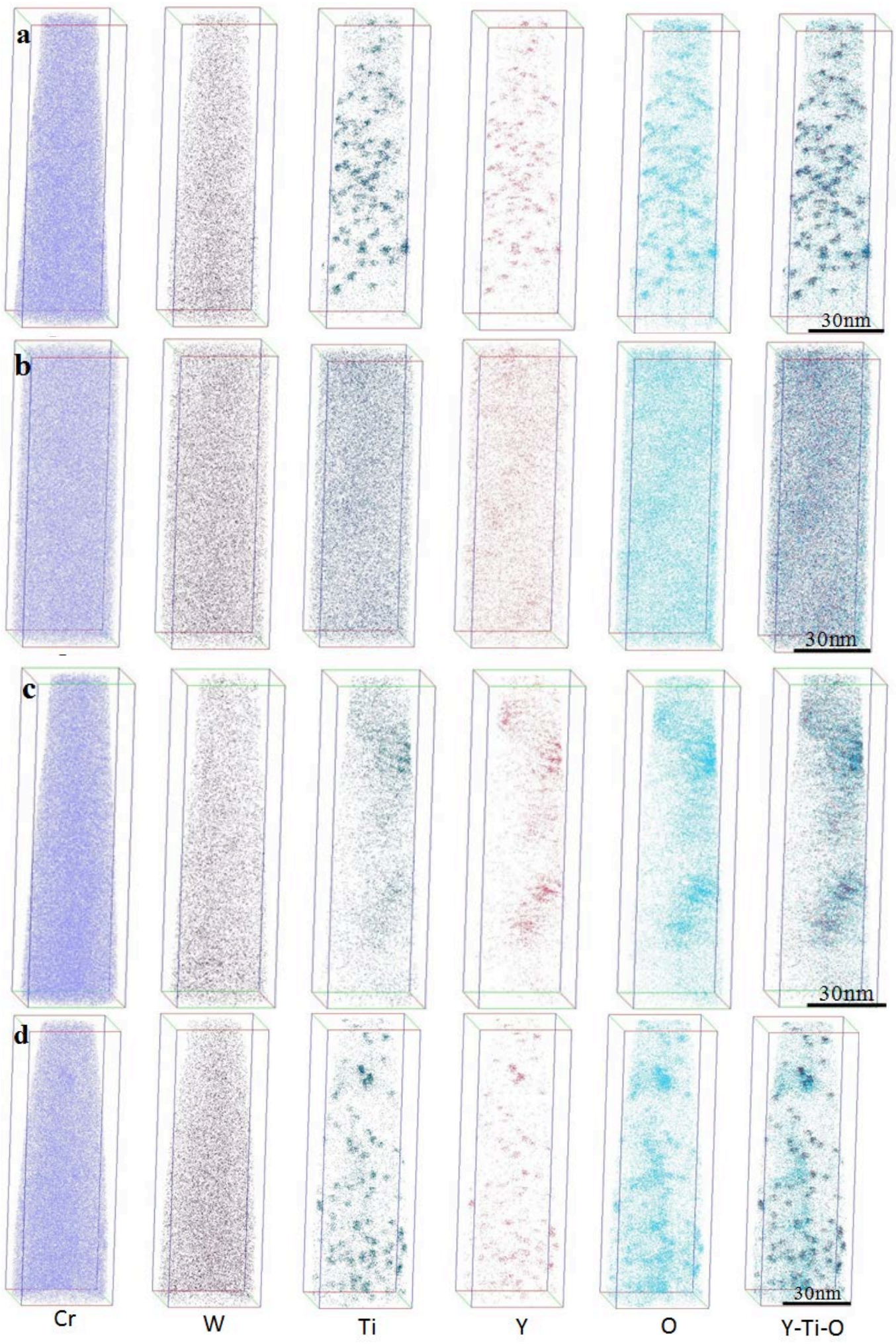

Figure 14. APT 3D reconstruction of 14YWT samples irradiated with $10 \mathrm{MeV}$ Pt ions (a) unirradiated sample (b) up to $100 \mathrm{dpa}$ at $-50^{\circ} \mathrm{C}$ (c) $100 \mathrm{dpa}$ at $200^{\circ} \mathrm{C}$ (d) $200 \mathrm{dpa}$ at $600^{\circ} \mathrm{C}$ 


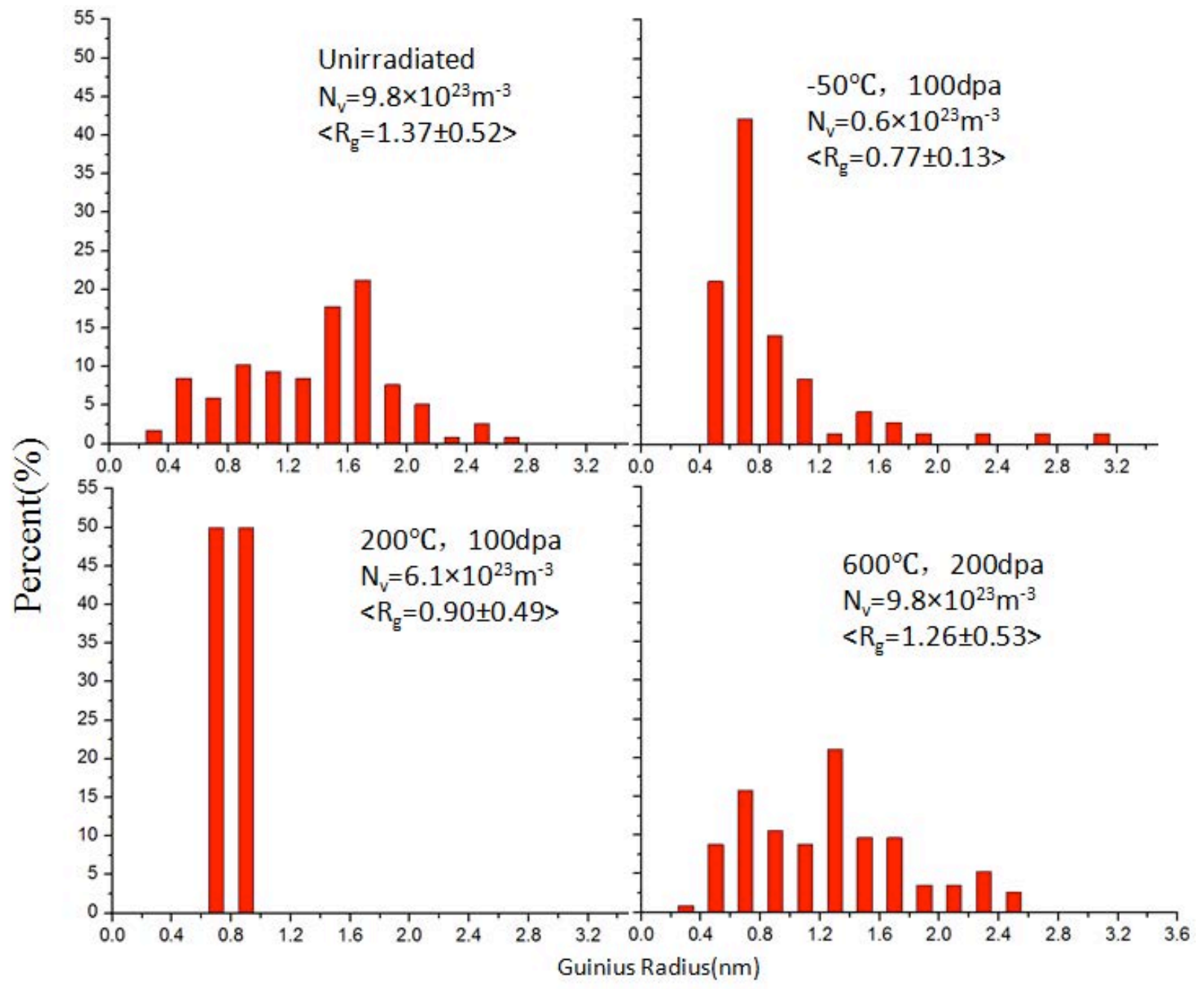

Figure 15. Nanocluster size distribution in unirradiated sample and irradiated samples 


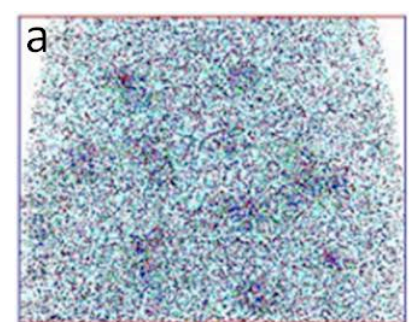

All
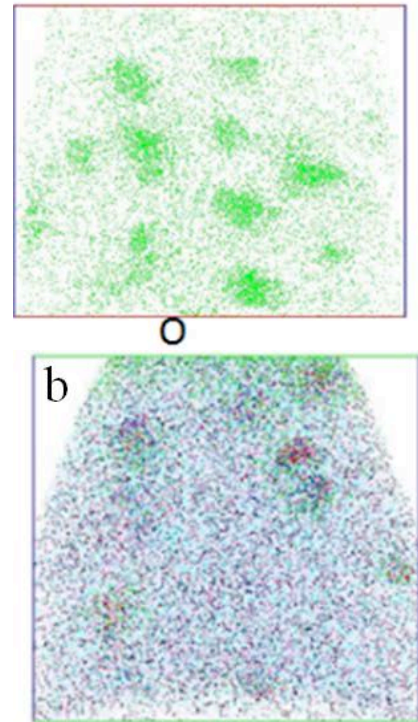

All

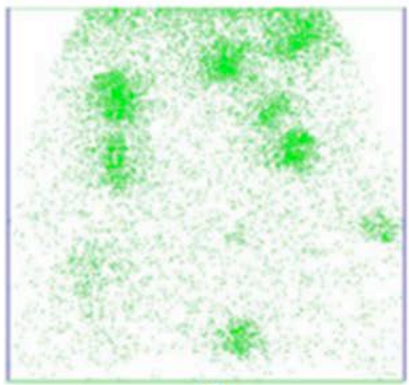

0

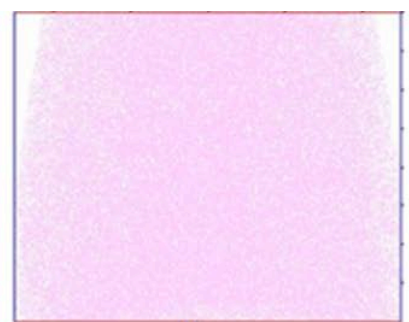

$\mathrm{Fe}$

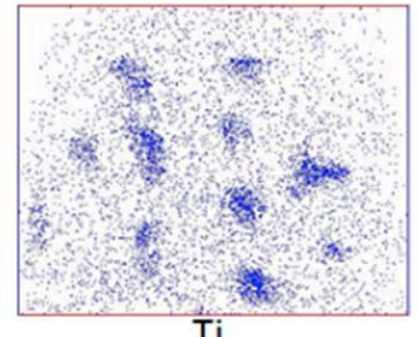

$\mathrm{Ti}$

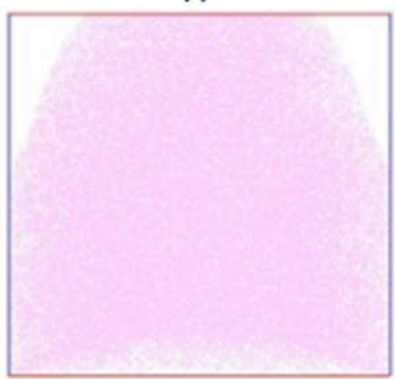

$\mathrm{Fe}$

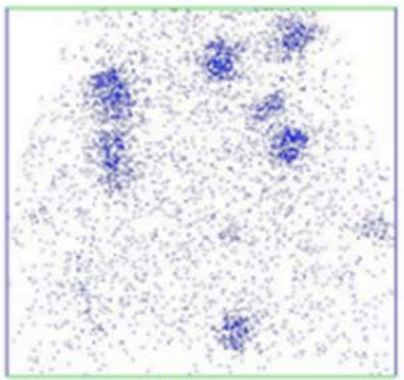

$\mathrm{Ti}$
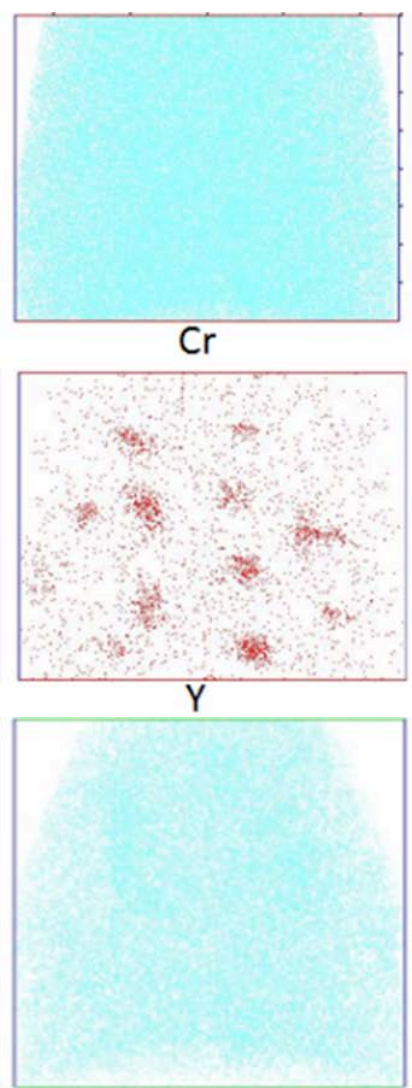

$\mathrm{Cr}$

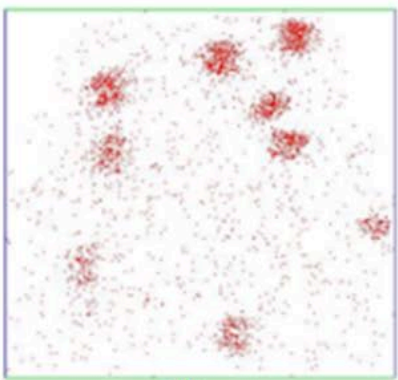

Y
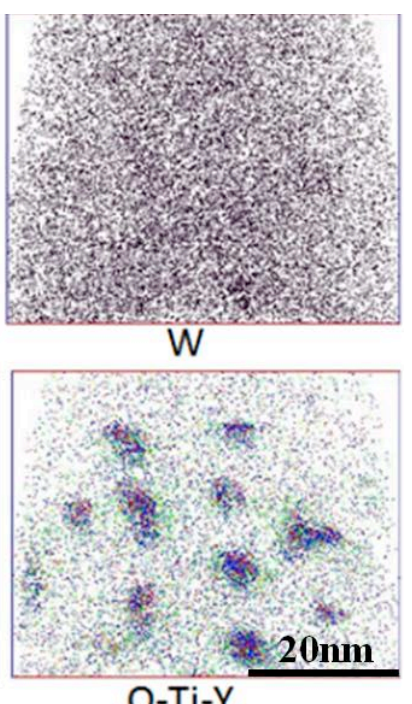

O-Ti-Y

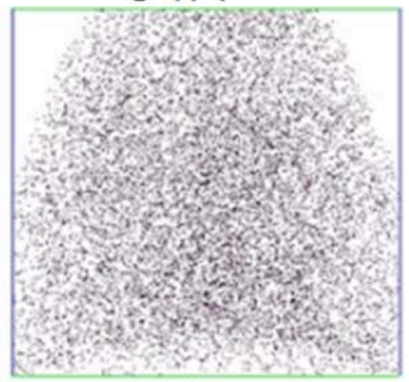

W

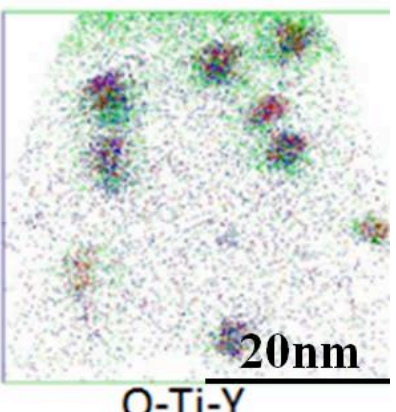

Figure 16. APT elemental maps of 9CrODS steel (a) before irradiation and (b) after proton irradiation to $3.7 \mathrm{dpa}$ at $400^{\circ} \mathrm{C}$. 


\subsection{Radiation-Induced Segregation}

Grain boundary $\mathrm{Cr}$ enrichment occurred in a bell-shaped temperature dependence between $300^{\circ} \mathrm{C}$ and $600^{\circ} \mathrm{C}$. A "crossover" temperature exists between $600^{\circ} \mathrm{C}$ and $700^{\circ} \mathrm{C}$ at which Cr RIS changes from enrichment to depletion.

The temperature dependence of RIS was studied in alloy T91 irradiated with $2.0 \mathrm{MeV}$ protons to $3 \mathrm{dpa}$ at temperatures ranging from $300^{\circ} \mathrm{C}$ to $700^{\circ} \mathrm{C}$. The change in grain boundary composition was averaged over all line scans collected from a given irradiation condition; these average RIS values are shown as a function of temperature in Figure 17. From this graph, it is clear that only small amounts of $\mathrm{Cr}$ RIS, never exceeding $\sim 2 \mathrm{wt} \%$, were observed. $\mathrm{Cr}$ enrichment and $\mathrm{Fe}$ depletion occurred in a bell-shaped temperature dependence between $300^{\circ} \mathrm{C}$ and $600^{\circ} \mathrm{C}$, but at $700^{\circ} \mathrm{C}$ the behavior reversed to $\mathrm{Cr}$ depletion and $\mathrm{Fe}$ enrichment. Minor elements ( $\left.\mathrm{Si}, \mathrm{Ni}, \mathrm{Cu}\right)$ segregation was observed between $400^{\circ} \mathrm{C}$ and $500^{\circ} \mathrm{C}$, enriching in a bell-shaped temperature dependence over this range. Chromium enrichment and $\mathrm{Fe}$ depletion were maximized at $450^{\circ} \mathrm{C}$, while enrichment of the minor elements $\mathrm{Si}, \mathrm{Ni}$, and $\mathrm{Cu}$ were maximized at $400^{\circ} \mathrm{C}$.

The bell-shaped temperature dependence can be attributed to point defect mobility. At low temperatures, defects are immobile and cannot diffuse to sinks, severely limiting the amount of segregation. At elevated temperatures, high point defect mobility induces back-diffusion, removing concentration gradients. Hence, the most segregation occurs at moderate temperatures. At the extreme temperatures of $300^{\circ} \mathrm{C}$ and $\geq 600^{\circ} \mathrm{C}$, some $\mathrm{Cr}$ and Fe RIS persisted, while minor element RIS was totally suppressed. This observation suggests that the mechanism of RIS of the minor elements differs than that of $\mathrm{Cr}$ and $\mathrm{Fe}$.

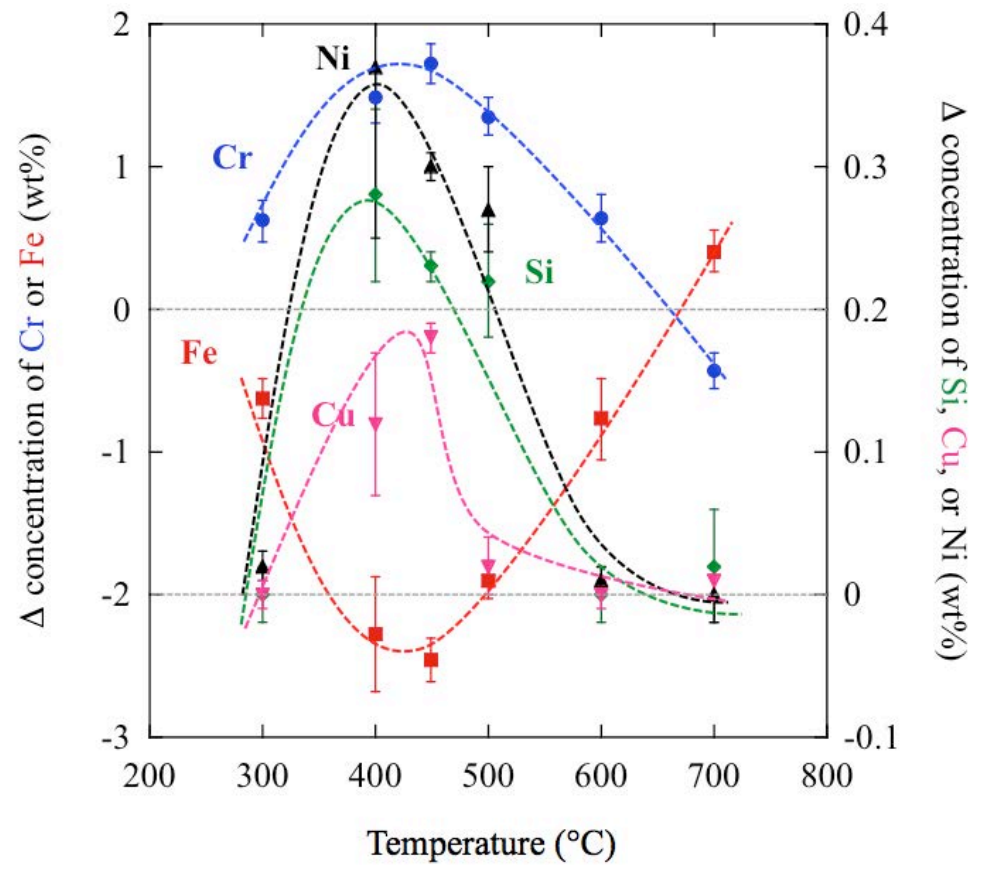

Figure 17. Average change in grain boundary concentration of $\mathrm{Cr}, \mathrm{Fe}, \mathrm{Si}, \mathrm{Cu}$, and $\mathrm{Ni} \mathrm{RIS}$ as a function of temperature, in T91 irradiated to 3 dpa with $2.0 \mathrm{MeV}$ protons. 
One of the most notable behaviors of RIS in F-M alloys is the "crossover" from Cr enrichment to $\mathrm{Cr}$ depletion (and also Fe depletion to Fe enrichment) between $600^{\circ} \mathrm{C}$ and $700^{\circ} \mathrm{C}$. This type of behavior has never been reported in any other alloy system. In this project, the crossover was also observed in alloy NF616, irradiated with $2.0 \mathrm{MeV}$ protons to $3 \mathrm{dpa}$ at $500^{\circ} \mathrm{C}$ and $700^{\circ} \mathrm{C}$. Figure 18 shows representative $\mathrm{Cr}$ RIS profiles from NF616, demonstrating $\mathrm{Cr}$ enrichment at $500^{\circ} \mathrm{C}$ reverting to $\mathrm{Cr}$ depletion at $700^{\circ} \mathrm{C}$.

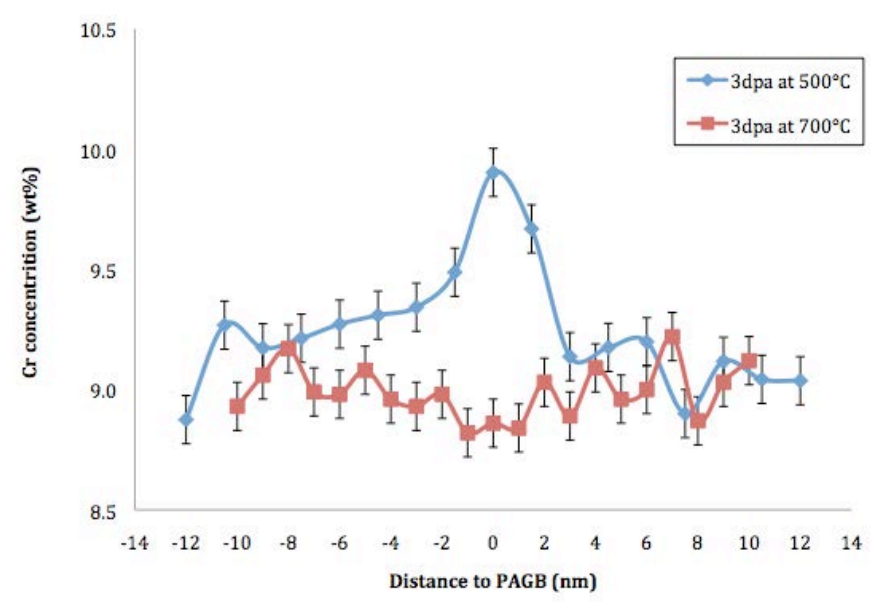

Figure 18. Representative Cr RIS profiles in NF616 irradiated to 3 dpa.

The average full width at half maximum (FWHM) of the Cr RIS profiles and the average area under the $\mathrm{Cr}$ enrichment peaks are shown in Figure 19 for T91 at 3 dpa. Not surprisingly, the area under the $\mathrm{Cr}$ enrichment peaks exhibited a bell-shaped temperature dependence, much like the change in grain boundary $\mathrm{Cr}$ concentration does. The FWHM of the $\mathrm{Cr}$ peaks however, increased as a function of temperature due to back-diffusion, which caused broadening of the $\mathrm{Cr}$ concentration gradient at elevated temperatures.

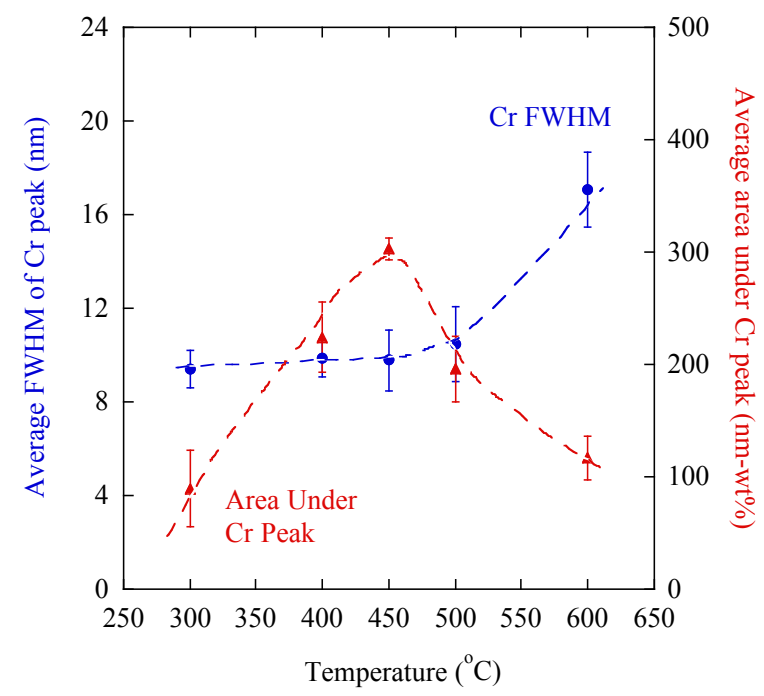

Figure 19. Average FWHM of peak and area under Cr RIS peak as a function of temperature, in T91 irradiated to $3 \mathrm{dpa}$ with $2.0 \mathrm{MeV}$ protons.

For additional details about RIS Accomplishment \#1, please view references [6-10]. 


\section{The behavior of $\mathrm{Cr}$ (and $\mathrm{Fe}$ ) RIS in F-M alloys was found to be largely consistent with the IK mechanism, supporting IK as the dominant mechanism of Cr RIS in F-M alloys.}

This study used a one-dimensional inverse Kirkendall (IK) model to calculate Cr RIS in a bcc Fe-Cr binary alloy system. The model simultaneously solves a system of equations representing the concentrations of the major alloying elements and the point defects, as a function of space and time. These equations are solved across a plane foil; one surface of the plane foil is fixed to simulate the grain boundary and to act as an unbiased point defect sink. Symmetry is assumed across the grain boundary. A number of inputs are required, but the model is most sensitive to four of them: the vacancy and migration energies of both $\mathrm{Cr}$ and Fe. Appropriate values for the $\mathrm{Fe}$ and $\mathrm{Cr}$ vacancy and interstitial migration energies were taken from various ab initio calculations published in the open literature, since limited experimental studies of these migration barriers provided only qualitative results. Furthermore, since the measured composition profile is the convolution of the actual composition profile with the electron beam, the model results were convoluted so as to provide a fair comparison with experimental measurements.

The IK model was able to reproduce the experimentally-measured temperature dependence of $\mathrm{Cr}$ $R I S$, within the known uncertainty range of the model input parameters. The IK model calculated RIS magnitudes almost identical to those measured experimentally when the dislocation density of $7.5 \times 10^{14} \mathrm{~m}^{-2}$ was used (Figure 20), which is consistent with the total sink strength of the material, as measured in reference [11]. Most importantly, the IK model predicted the crossover between $\mathrm{Cr}$ enrichment and $\mathrm{Cr}$ depletion between $600^{\circ} \mathrm{C}$ and $700^{\circ} \mathrm{C}$.

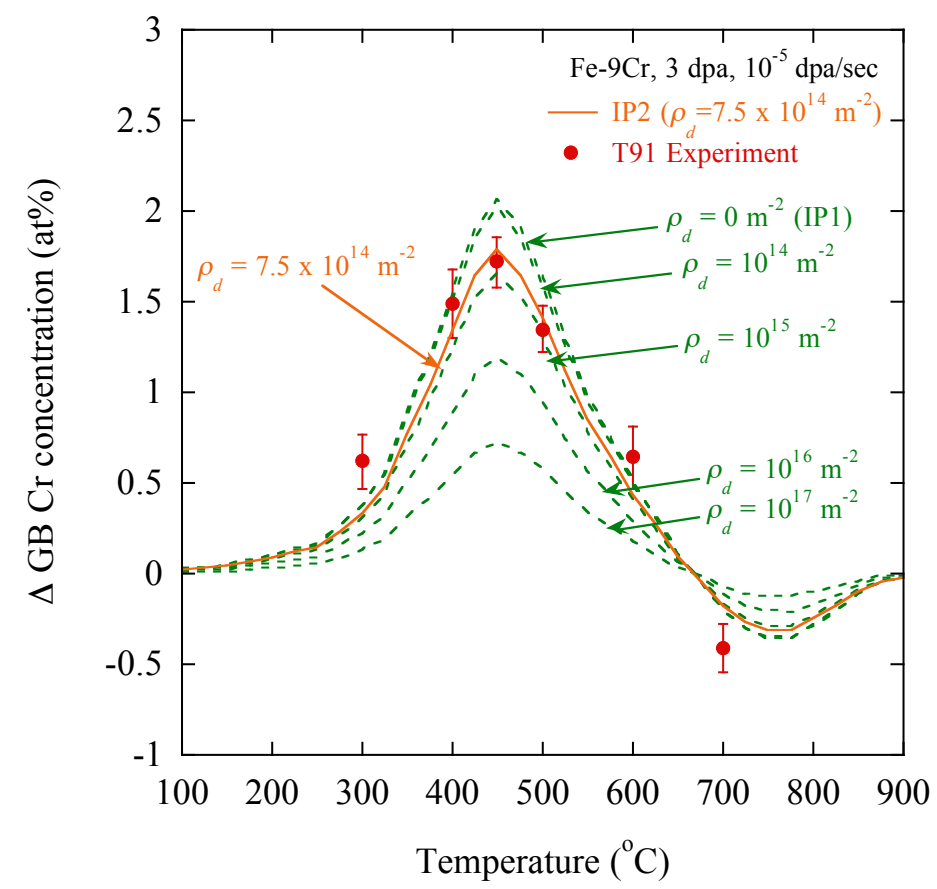

Figure 20. Effect of sink density on temperature dependence of IK modeled Cr RIS for Fe-9Cr, compared with experimental measurements from T91, at $3 \mathrm{dpa}, 10^{-5} \mathrm{dpa} / \mathrm{sec}$. 
The crossover can be explained by the diffusion coefficient ratios of $\mathrm{Cr}$ to $\mathrm{Fe}$ for both vacancies and interstitials. The crossover occurs because the ratio of the vacancy diffusion coefficient in $\mathrm{Cr}$ to that in $\mathrm{Fe}$ crosses the ratio for interstitials, resulting in a change in Cr RIS direction. When the interstitial and vacancy diffusion coefficient ratios are equal (i.e. at the crossover), the contribution of $\mathrm{Cr}$ enrichment by interstitials is balanced by the contribution of $\mathrm{Cr}$ depletion by vacancies. Below the crossover temperature, $\mathrm{Cr}$ enrichment by interstitials dominates $\mathrm{Cr}$ depletion by vacancies, resulting in a net $\mathrm{Cr}$ enrichment. Conversely, above the crossover temperature, $\mathrm{Cr}$ depletion by vacancies dominates $\mathrm{Cr}$ enrichment by interstitials, resulting in a net $\mathrm{Cr}$ depletion.

The IK model was also able to reproduce the measured dependence of $\mathrm{Cr} R I S$ on bulk $\mathrm{Cr}$ concentration. When concentration-dependent interstitial migration energies were input, the IK model predicted decreasing $\mathrm{Cr}$ enrichment with increasing $\mathrm{Cr}$ concentration, consistent with experiments (Figure 21). This observation can also be explained by the diffusion coefficient ratios of $\mathrm{Cr}$ to $\mathrm{Fe}$ for both vacancies and interstitials. Implementing composition-dependent interstitial migration energies caused the interstitial diffusion coefficient ratio of $\mathrm{Cr}$ to $\mathrm{Fe}$, to change, as illustrated in Figure 22 for the 11-12 wt \% Cr interstitial migration energies (solid line) compared to the original $9 \mathrm{wt} \% \mathrm{Cr}$ interstitial migration energies (dashed line). The shift in the interstitial diffusion coefficient ratio caused two significant effects: (1) the crossover temperature decreased to $\sim 550^{\circ} \mathrm{C}$, and (2) the difference between the vacancy and interstitial diffusion coefficient ratios at $400^{\circ} \mathrm{C}$ decreased. The latter of these effects explains the observed decrease in $\mathrm{Cr}$ enrichment as a function of increasing bulk $\mathrm{Cr}$ concentration.

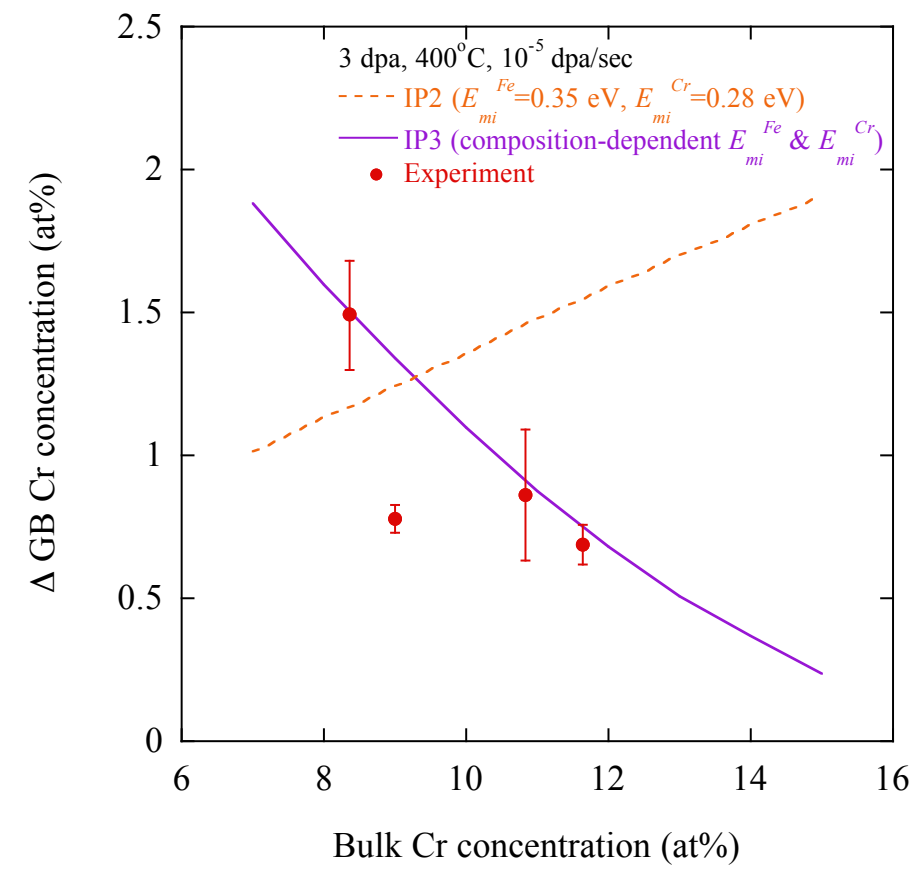

Figure 21. Comparison of composition dependence of Cr RIS between IK model and experimental measurements at $400^{\circ} \mathrm{C}, 3 \mathrm{dpa}, 10^{-5} \mathrm{dpa} / \mathrm{sec}$. 


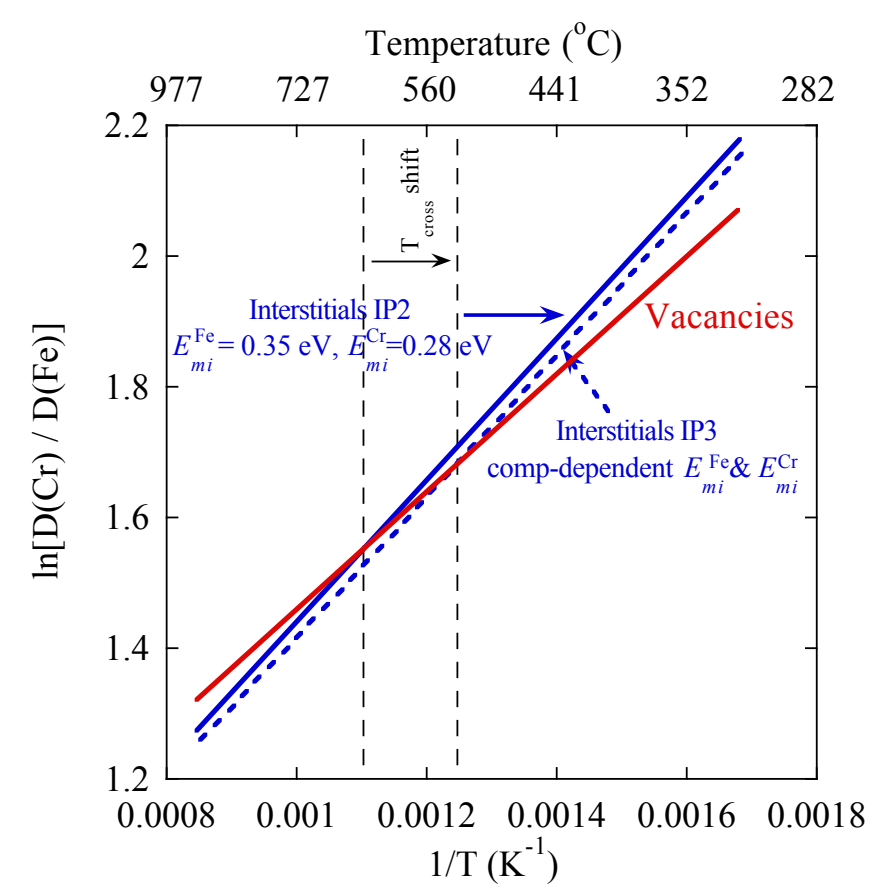

Figure 22. Effect of composition-dependent interstitial migration energies on the $\mathrm{Cr}$ to $\mathrm{Fe}$ interstitial diffusion coefficient ratio for $11-12 \mathrm{wt} \% \mathrm{Cr}$ (solid lines) compared to that for $9 \mathrm{wt} \%$ $\mathrm{Cr}$ (dashed line).

An alternative RIS mechanism, the solute drag mechanism, was also investigated. This mechanism considers both solute-interstitial and solute-vacancy complexes. Solute-interstitial complexes are considered as di-interstitial dumbbells. For solute-vacancy complexes, atomic species strongly bound to vacancies would be carried, or "dragged", along with the vacancy flux to grain boundaries. In this work, the solute drag mechanism was modeled by adding the diffusion of solute-vacancy and solute-interstitial complexes to the existing IK model presented earlier.

The binding energies of Cr-interstitial and Cr-vacancy complexes are positive, suggesting that the solute drag mechanism will always produce $\mathrm{Cr}$ enrichment. Thus, it is clear that the solute drag mechanism is unable to account for the crossover from $\mathrm{Cr}$ enrichment to $\mathrm{Cr}$ depletion. Therefore, $\mathrm{Cr}$ depletion will not occur if solute drag is a dominant process. And indeed, the model that included the solute drag mechanism demonstrated that the IK mechanism cannot account for Cr-interstitial binding, confirming that attractive Cr-vacancy and Cr-interstitial binding cannot explain $\mathrm{Cr}$ depletion.

The RIS measurements from this study are consistent with the IK mechanism. A more rigorous test, however, is to determine whether RIS measurements from the literature can be explained by the IK mechanism. The IK model predicts a concentration-dependent crossover temperature; this trend is an effective way to compare the IK mechanism to literature measurements, as shown in Figure 23. Observations of $\mathrm{Cr}$ enrichment should fall below the crossover temperature line, while observations of $\mathrm{Cr}$ depletion should fall above the crossover. It is recognized that while the literature data are predominantly from commercial alloys containing a number of minor elements, the IK model does not account for elements other than Fe and Cr. The effect of minor 
elements on the crossover temperature, and on Cr RIS behavior in general, is not well known. However, the good match between measurement and model for the temperature dependence of RIS in T91 using sink densities that are close to those calculated from the measured microstructure, indicate that the effect of the minor elements cannot be large. Thus, the crossover temperature for T91 is likely close to that for Fe-Cr.

The majority of RIS measurements from the open literature reported that the direction of Cr RIS is consistent with the IK model prediction for the given alloy composition (open triangles in Figure 23). Two studies observed no $\mathrm{Cr}$ segregation (open circles); these studies have bulk $\mathrm{Cr}$ compositions and temperatures that fall close to the IK-predicted crossover line, which is reasonable. Several experiments were conducted using techniques that make it difficult to determine the true direction of $\mathrm{Cr}$ RIS (open squares). However, in general, the RIS measurements from the open literature fall into good agreement with the crossover temperature line calculated from the IK model in this study.
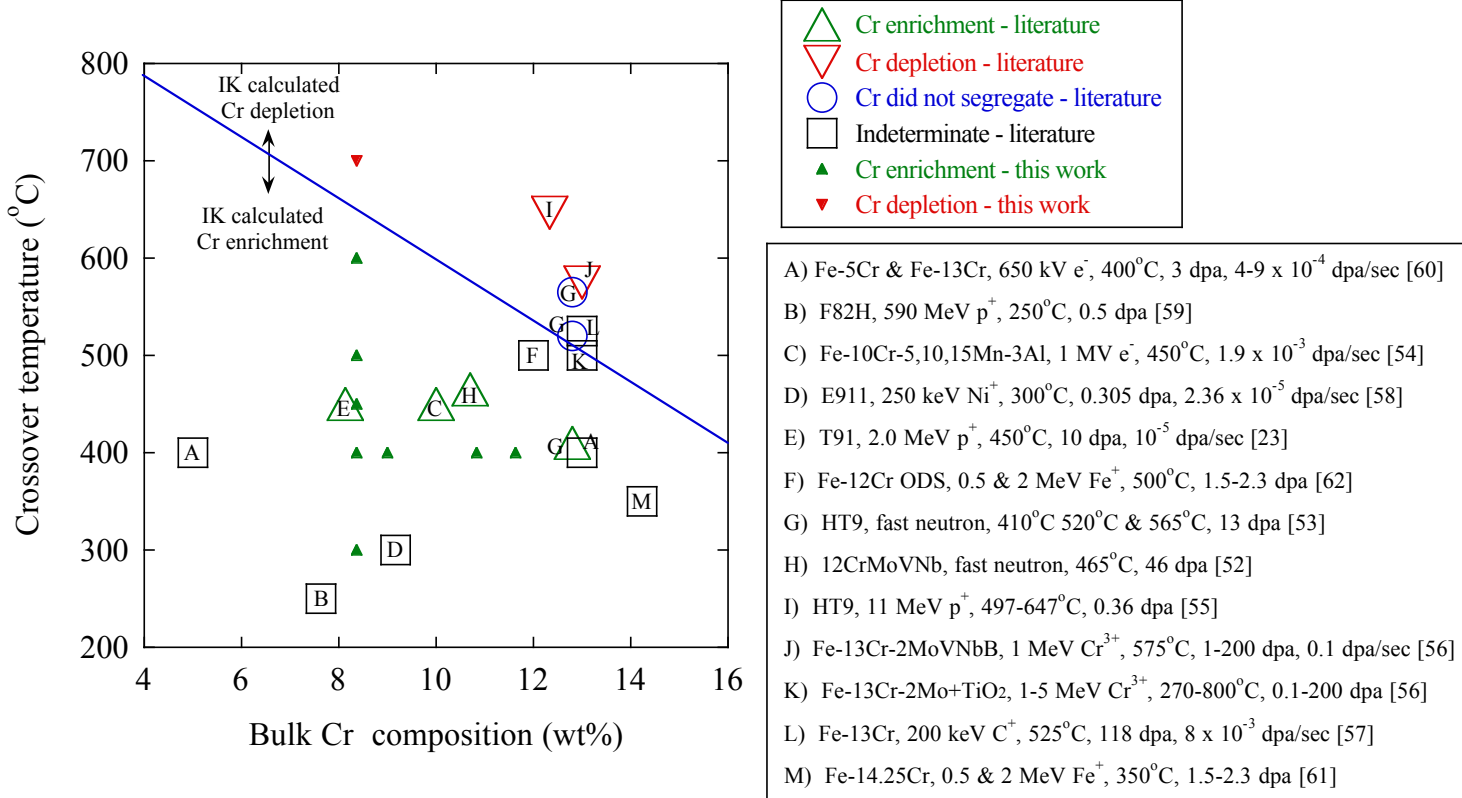

Figure 23. Experimental measurements of the directions of Cr RIS in F-M alloys published in the literature (open symbols), as compared to the crossover temperature calculated in this work and experimental measurements of Cr RIS from (closed symbols). 


\subsection{Irradiation Creep}

The stress dependence of the irradiation creep rate of alloy T91 is found to be linear below $160 \mathrm{MPa}$ and follows power law behavior above $160 \mathrm{MPa}$.

Irradiation creep of T91 was investigated using in-situ proton irradiations with $3.0 \mathrm{MeV}$ protons at temperatures in the range $400-500^{\circ} \mathrm{C}$, stresses of $100-200 \mathrm{MPa}$ up to 1-2 dpa. The detailed experimental setup for proton irradiation creep are discussed by $\mathrm{Xu}$ et al. [13]. Experiments were designed to isolate the stress dependence of primary creep, and allow an in-depth analysis of anisotropy of the irradiation creep microstructure. The full table of experiments and strain rate results are tabulated in Table 7.

Results of measured irradiation creep rates as a function of stress are shown in Figure 24. The strain rate behavior can be empirically fit by a combination of a linear stress dependence and power law stress dependence. The linear stress behavior at low stress is consistent with irradiation creep driven by dislocation climb, while the power law stress behavior at high stress is consistent with creep behavior driven by dislocation glide [14]. The stress at which dislocation glide overtakes dislocation climb is observed to be $160 \mathrm{MPa}$ for irradiation creep. This value is similar to the $170 \mathrm{MPa}$ turnover stress observed by Haney et al [15] for thermal creep of T91 at $500^{\circ} \mathrm{C}$. The measurements for the irradiation creep experiments suggest dislocations are responsible for the strain rate behavior of ferritic-martensitic steel T91.

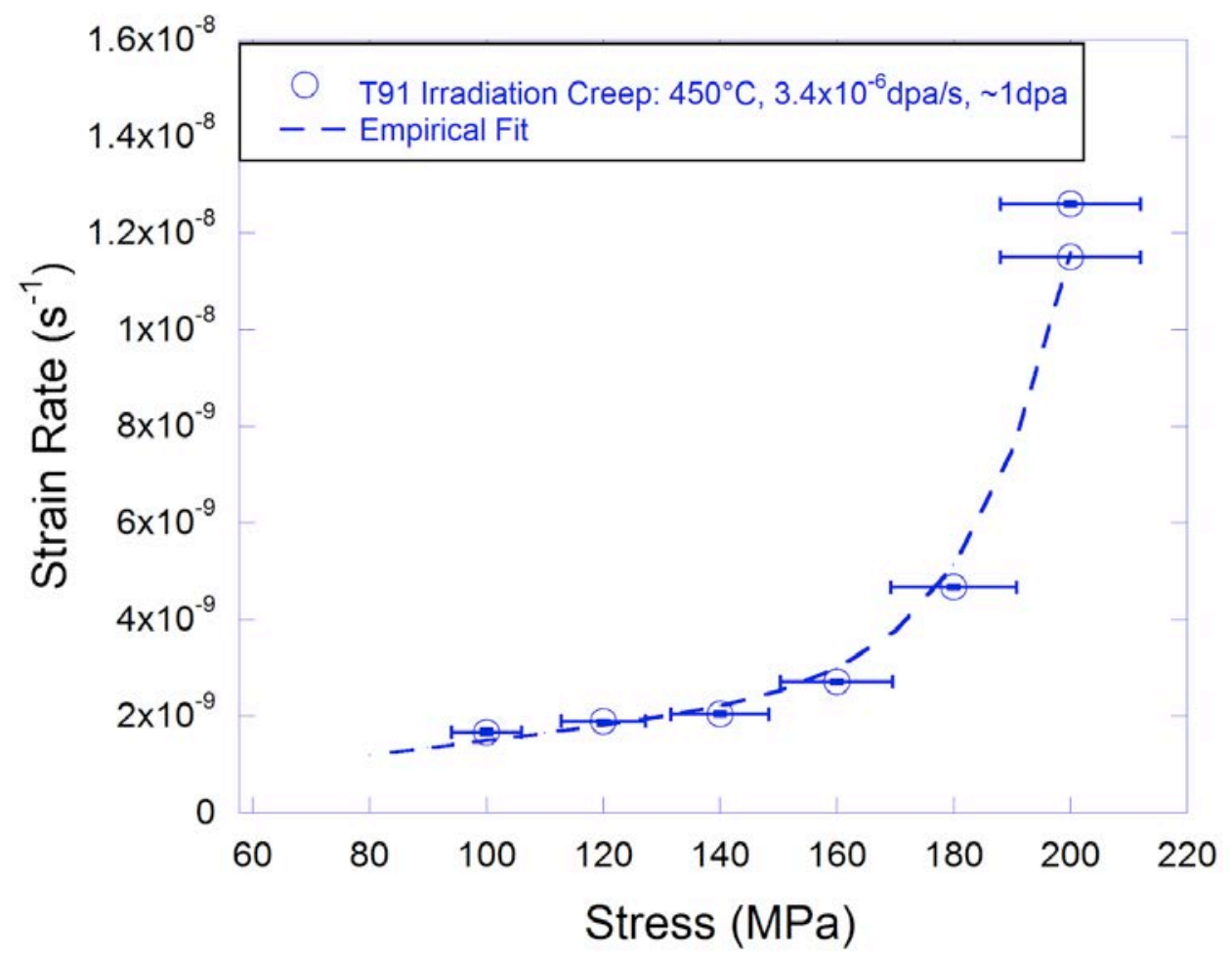

Figure 24. Stress dependence of irradiation creep of T91 at $450^{\circ} \mathrm{C}$. 
Table 7. Sample conditions and strain rate of all irradiation creep experiments

\begin{tabular}{|l|l|l|l|l|l|l|l|}
\hline $\begin{array}{l}\text { Sample } \\
\text { Name }\end{array}$ & Alloy & $\begin{array}{l}\text { Temperature } \\
\left({ }^{\circ} \mathrm{C}\right)\end{array}$ & $\begin{array}{l}\text { Stress } \\
(\mathrm{MPa})\end{array}$ & $\begin{array}{l}\text { Dose } \\
\text { Rate } \\
(\mathrm{dpa} / \mathrm{s})\end{array}$ & $\begin{array}{l}\text { Dose } \\
(\mathrm{dpa})\end{array}$ & $\begin{array}{l}\text { Strain Rate } \\
\left(10^{-9} \mathrm{~s}^{-1}\right)\end{array}$ & $\begin{array}{l}\text { Statistic } \\
\text { Error } \\
1\end{array}$ \\
\hline IT400160-A & T91 & 400 & 160 & $2.6 \times 10^{-6} \mathrm{~s}$ \\
\hline IT450000-A & T91 & 450 & 0 & $3.4 \times 10^{-6}$ & 1 & 2.9 & 0.11 \\
\hline IT450100-A & T91 & 450 & 100 & $3.4 \times 10^{-6}$ & 2 & 1.67 & 0.06 \\
\hline IT450120-A & T91 & 450 & 120 & $3.4 \times 10^{-6}$ & 1 & 1.9 & 0.025 \\
\hline IT450140-A & T91 & 450 & 140 & $3.4 \times 10^{-6}$ & 1 & 2.05 & 0.04 \\
\hline IT450160-A & T91 & 450 & 160 & $3.4 \times 10^{-6}$ & 1 & 2.7 & 0.035 \\
\hline IT450180-A & T91 & 450 & 180 & $3.4 \times 10^{-6}$ & 1 & 4.67 & 0.037 \\
\hline IT450180-B & T91 & 450 & 180 & $3.4 \times 10^{-6}$ & 1 & 5.00 & 0.03 \\
\hline IT450200-A & T91 & 450 & 200 & $3.4 \times 10^{-6}$ & 1 & 12.5 & 0.053 \\
\hline IT450200-B & T91 & 450 & 200 & $3.4 \times 10^{-6}$ & 1 & 11.5 & 0.032 \\
\hline IT500160-A & T91 & 500 & 160 & $* 3 \times 10^{-6}$ & 1.5 & 1.78 & 0.16 \\
\hline IT500160-A & T91 & 500 & 160 & $* 3.4 \times 10^{-6}$ & 0.8 & 2.33 & 0.096 \\
\hline IT500160-A & T91 & 500 & 160 & $* 4.8 \times 10^{-6}$ & 1.2 & 5.08 & 0.13 \\
\hline IT500180-A & T91 & 500 & 180 & $1 \times 10^{-5}$ & 1 & 5.78 & 0.25 \\
\hline IH450160-A & HT9 & 450 & 160 & $3.4 \times 10^{-6}$ & 1 & 3.4 & 0.07 \\
\hline IA450160-A & HCM12A & 450 & 160 & $3.4 \times 10^{-6}$ & 1 & 5.85 & 0.02 \\
\hline TT450200-A & T91 & 450 & 200 & 0 & 0 & 1.4 & 0.002 \\
\hline TT500200-A & T91 & 500 & 200 & 0 & 0 & 12.8 & 0.032 \\
\hline TT500200-B & T91 & 500 & 200 & 0 & 0 & 11.5 & 0.042 \\
\hline
\end{tabular}

The anisotropy in the dislocation loop density is observed to increase linearly with stress. Loop size distribution is correlated to both stress and irradiation time.

Four irradiation creep samples were analyzed by TEM for identification of unique irradiation creep microstructure. The method for quantifying localized dislocation loop anisotropy was developed so as to preserve the tensile axis direction throughout the analysis. TEM analysis of the irradiation creep microstructure revealed evidence of stress induced preferential nucleation (SIPN) as shown by the anisotropy in the dislocation loop density. 
Figure 25 plots the local anisotropy of the dislocation loop density and dislocation loop size of irradiation creep samples. The x-axis in Figure 25 is defined by the angle between the loop normal and the tensile axis. The dislocation loop density is defined by the grain normalized loop count shown as blue data points in Figure 25. The dislocation loop density is found to have a linear dependence on the orientation to the tensile axis. The higher the applied tensile stress, the larger the effect of the anisotropy on the loop density. The observed anisotropy in dislocation loop density as a function of stress is evidence for preferred nucleation of dislocation loops, lending credibility to the operation of SIPN irradiation creep mechanism [16].

The same localized anisotropy found for dislocation loop density was not found for dislocation loop size as shown by the data points in red in Figure 25. However, the applied stress does act to increase the overall size of dislocation loops. Figure 26 illustrates the dislocation loop size distribution for all four irradiation creep conditions. The dislocation loop size for $200 \mathrm{MPa}$ condition is a significantly larger than those of $180 \mathrm{MPa}$. The loop size of the $180 \mathrm{MPa}$ conditions are comparable to those found for $100 \mathrm{MPa}$ despite only having half of the total dose. The observations from the TEM analysis determined that dislocation loops is both a function of applied stress and the irradiation dose. 
a)

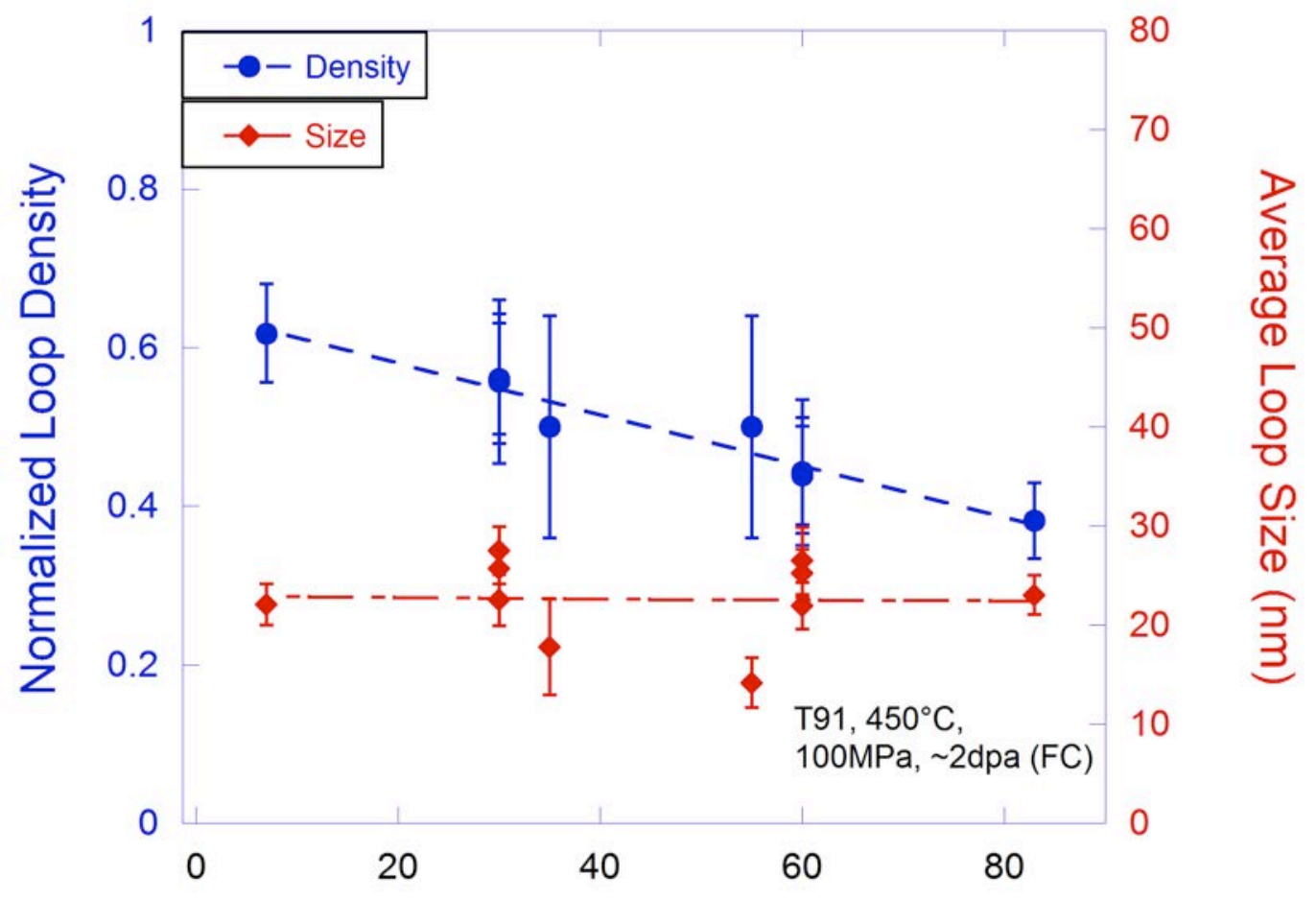

Angle Between Loop Normal and Tensile Axis

b)

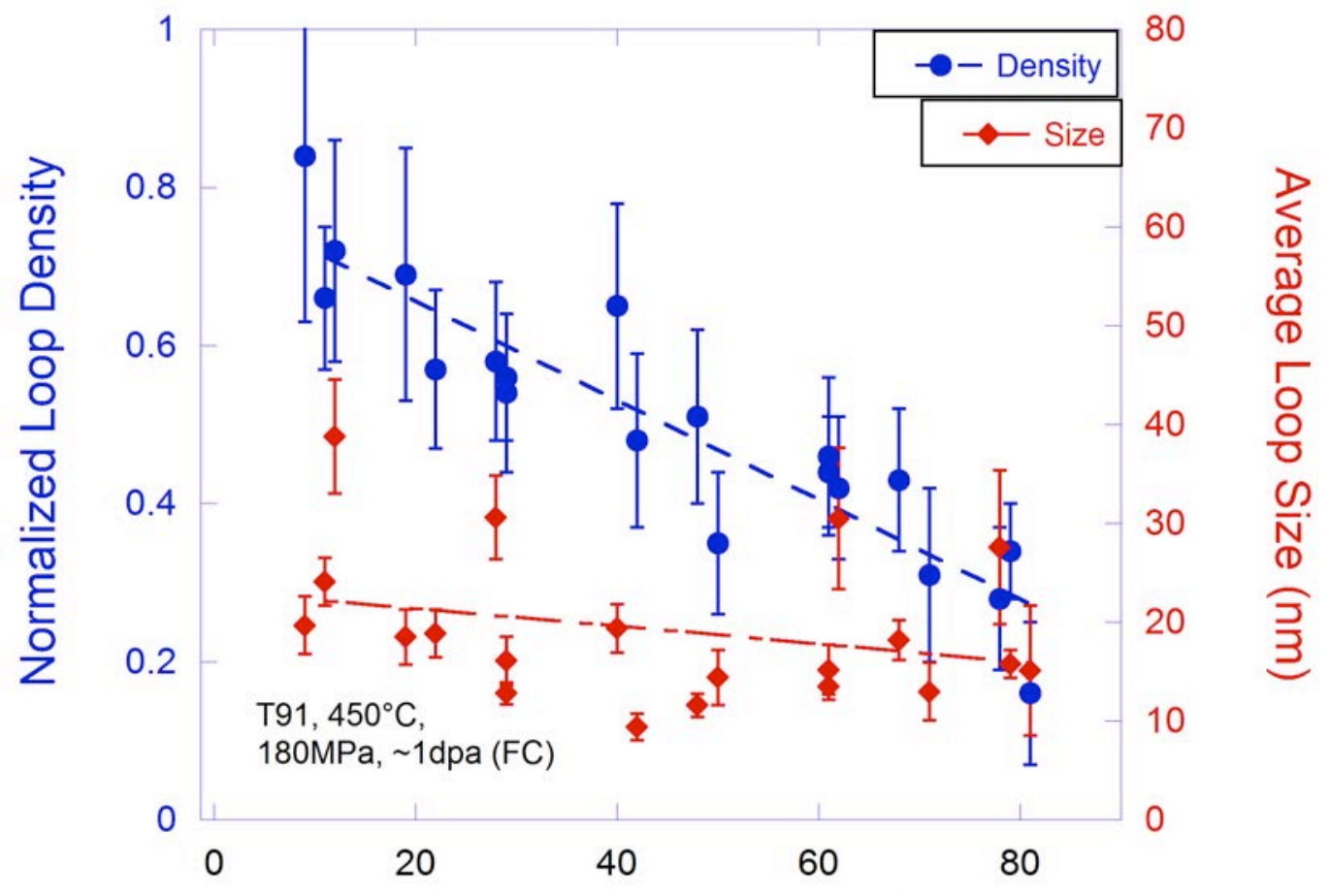

Angle Between Loop Normal and Tensile Axis 
c)

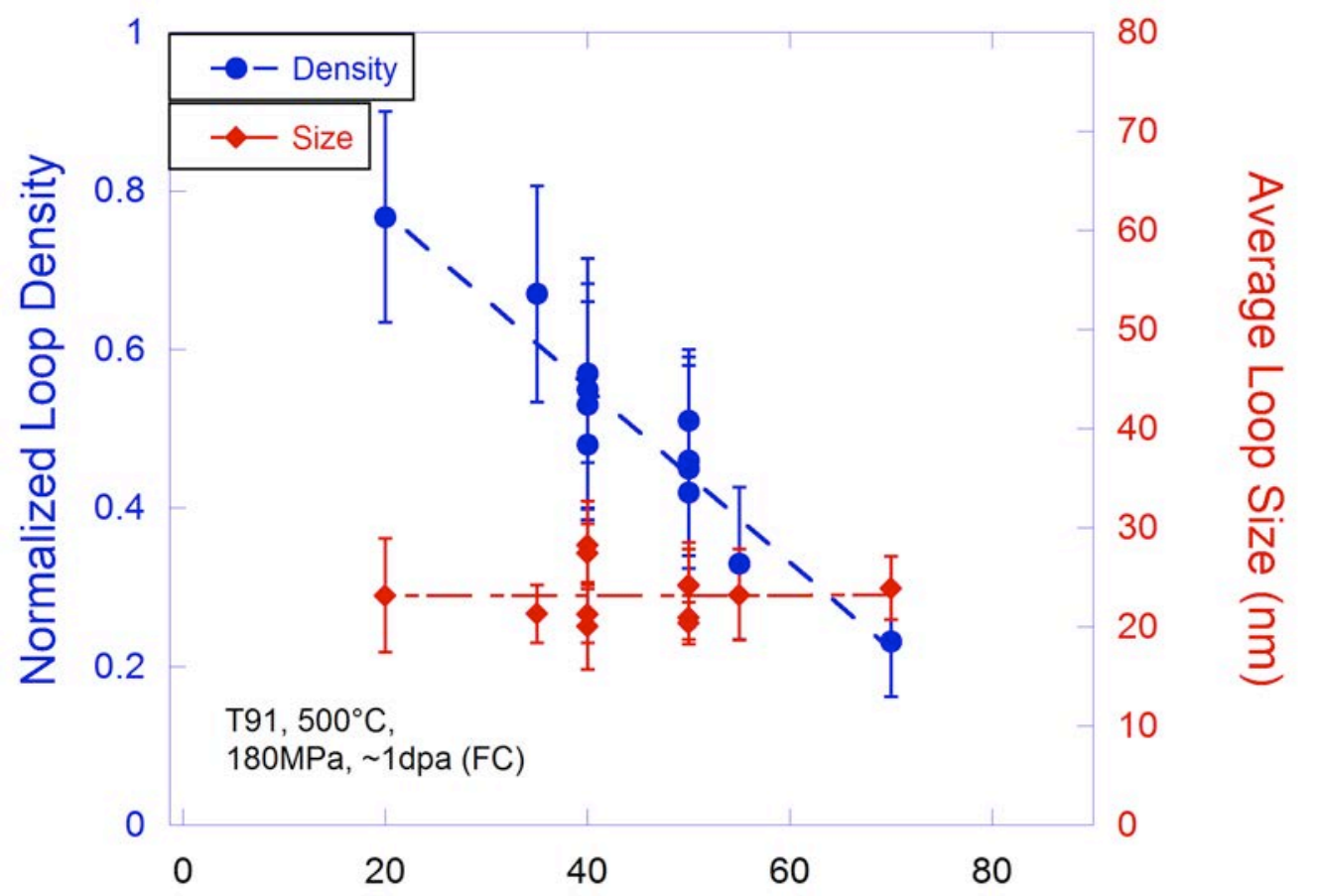

Angle Between Loop Normal and Tensile Axis

d)

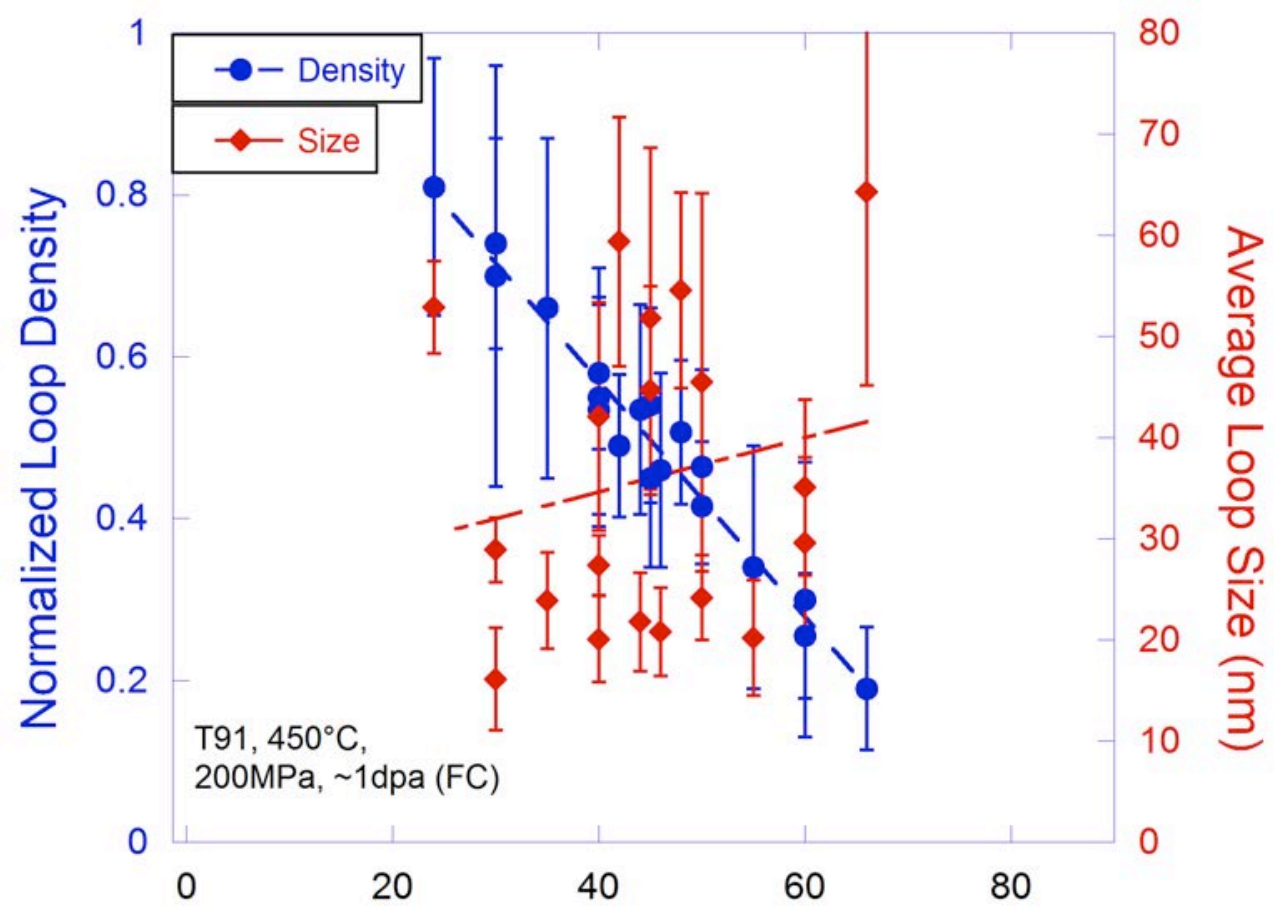

Angle Between Loop Normal and Tensile Axis

Figure 25. Loop anisotropy plot of the irradiation creep experiments for a) IT450100, b) IT450180, c) IT500180, d) IT450200. 
a)

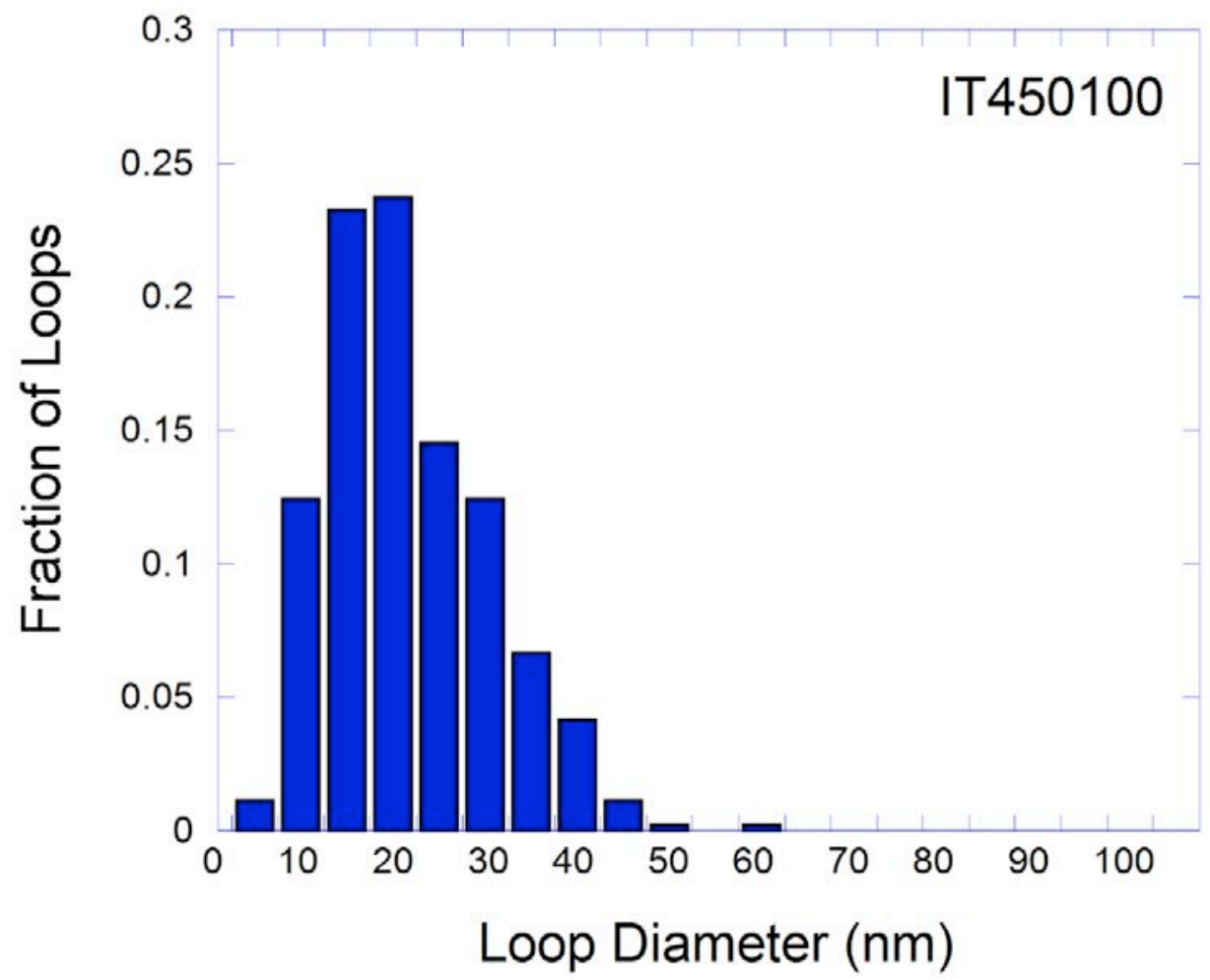

b)

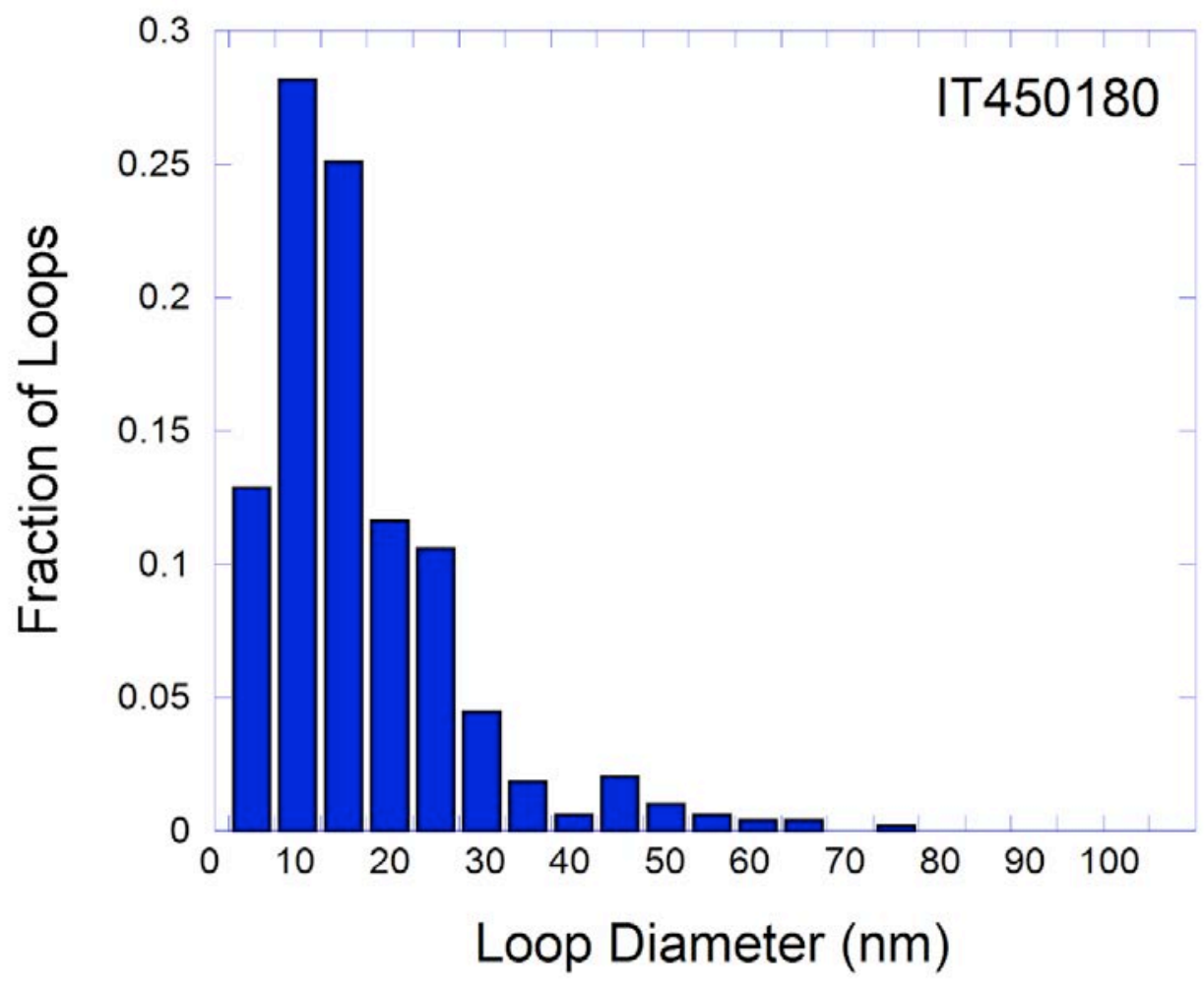




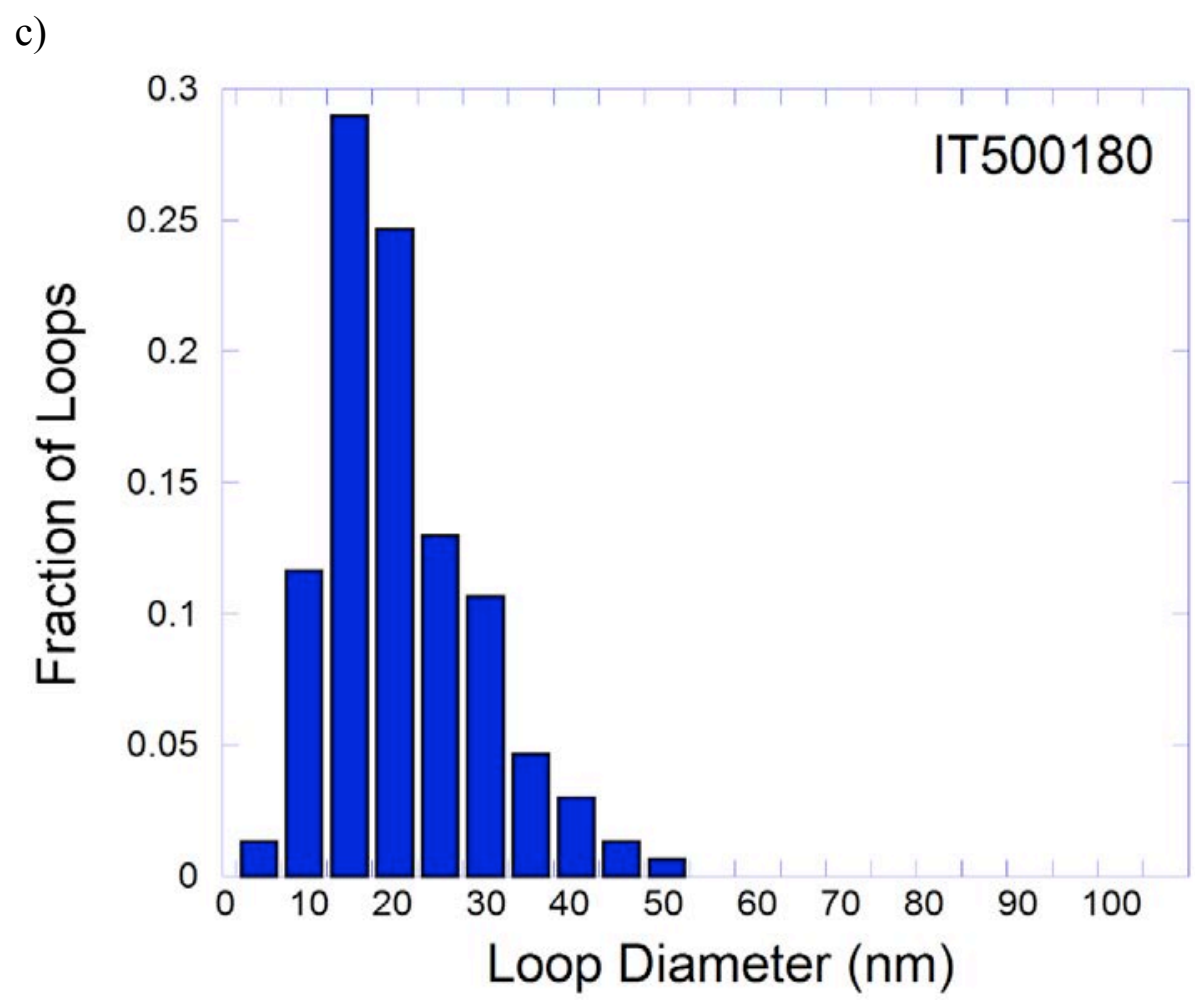

d)

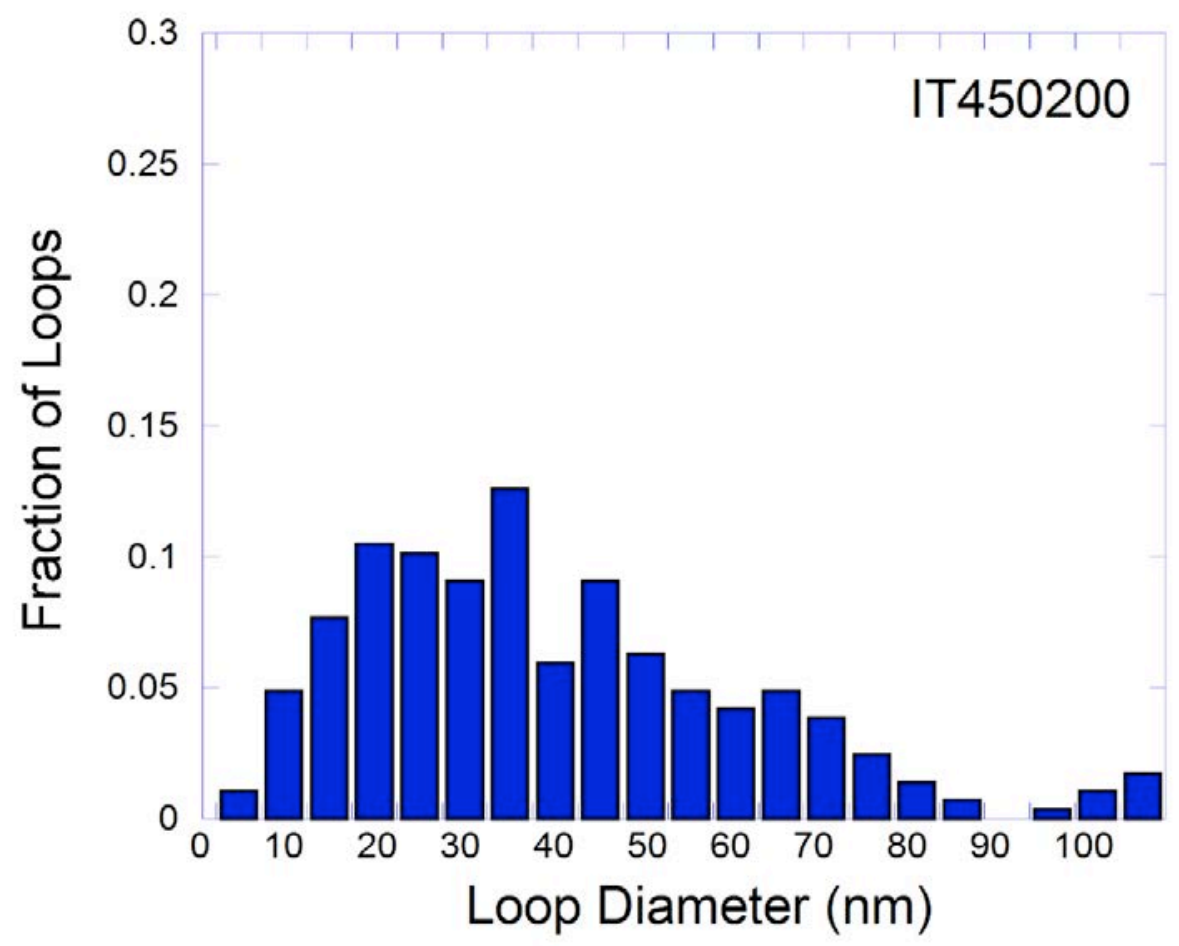

Figure 26. Loop size spectrum of irradiation creep samples, a) IT450100, b) IT450180, c) IT500180, d) IT450200. 


\section{The SIPN contribution to irradiation creep strain is calculated based on observed anisotropy in the dislocation loop density.}

The strain contribution of the dislocation loops are calculated based on TEM observations by carefully accounting for the loop density, loop size, and loop orientation to the tensile axis. Semiempirical equations are developed to link experimental TEM observations with macroscopic strains that are consistent with the theoretical description. The semi-empirical approach is capable of determining SIPN strain in all three primary directions for a grain situated at any direction relative to the tensile axis is shown in Figure 27. The orientation of any grain relative to the tensile axis is uniquely defined by the angles $\theta$ and $\phi$. A typical plot of the SIPN contribution as a function of grain orientation is shown in Figure 28.

The result of the SIPN calculations are compared with the total macroscopic strain tabulated in Table 8 . The maximum SIPN contribution are found to account for $6-37 \%$ of the total strain measured. The longer the irradiation, the less SIPN contributes to the total strain. This observation confirms that SIPN is a transient phenomenon that mainly affects the primary regime of irradiation creep. SIPN is found to be insufficient to fully account for all the irradiation creep strain observed in the sample.

The remaining irradiation creep strain could be explained by preferential absorption of point defects. Although an accurate empirical treatment of the SIPA contribution requires detailed analysis of dislocation network Burgers vector that was not included in the scope of this project, there is indirect macroscopic and microscopic evidence that points to the operation of SIPA. The stress dependence of T91 irradiation creep is found to be linear under $160 \mathrm{MPa}$ and higher than linear above 160MPa. This is consistent with the theoretical understanding of creep by preferred absorption of point defects (SIPA) resulting in dislocation climb at low stress, and dislocation glide at high stress [14], [17]. In addition, the effect of applied stress on the dislocation loop size is further evidence for SIPA as the creep mechanism that is operating in addition to SIPN in T91. SIPN and SIPA are identified as the most likely dominant primary irradiation creep mechanism in T91 through irradiation experiments and microstructural analysis. The anisotropy in the microstructure of the material plays a significant importance in the irradiation creep behavior of ferritic-martensitic steels.

Table 8. TEM analysis irradiation creep sample conditions and SIPN strains.

\begin{tabular}{|l|l|l|l|l|l|l|l|l|}
\hline $\begin{array}{l}\text { Sample } \\
\text { Name }\end{array}$ & $\begin{array}{l}\text { Dose } \\
(\mathrm{dpa})\end{array}$ & $\begin{array}{l}\text { Dose Rate } \\
(\mathrm{dpa} / \mathrm{s})\end{array}$ & $\begin{array}{l}\text { Temp } \\
\left({ }^{\circ} \mathrm{C}\right)\end{array}$ & $\begin{array}{l}\text { Applied } \\
\text { Stress } \\
(\mathrm{MPa})\end{array}$ & $\begin{array}{l}\text { Irradiation } \\
\text { Time } \\
(\text { Hours })\end{array}$ & $\begin{array}{l}\text { Max } \\
\text { Calculated } \\
\text { SIPN Strain } \\
(\%)\end{array}$ & $\begin{array}{l}\text { Measured } \\
\text { Total } \\
\text { Strain } \\
(\%)\end{array}$ & $\begin{array}{l}\text { Percent } \\
\text { of SIPN } \\
\text { Strain } \\
(\%)\end{array}$ \\
\hline IT450100-A & $\sim 2$ & $3.4 \times 10^{-6}$ & 450 & 100 & 170 & 0.006 & 0.10 & 6 \\
\hline IT500180-A & 1 & $1 \times 10^{-5}$ & 500 & 180 & 30 & 0.022 & 0.06 & 37 \\
\hline IT450180-A & 1 & $3.4 \times 10^{-6}$ & 450 & 180 & 80 & 0.021 & 0.13 & 15 \\
\hline IT450200-A & 1 & $3.4 \times 10^{-6}$ & 450 & 200 & 80 & 0.040 & 0.36 & 11 \\
\hline
\end{tabular}




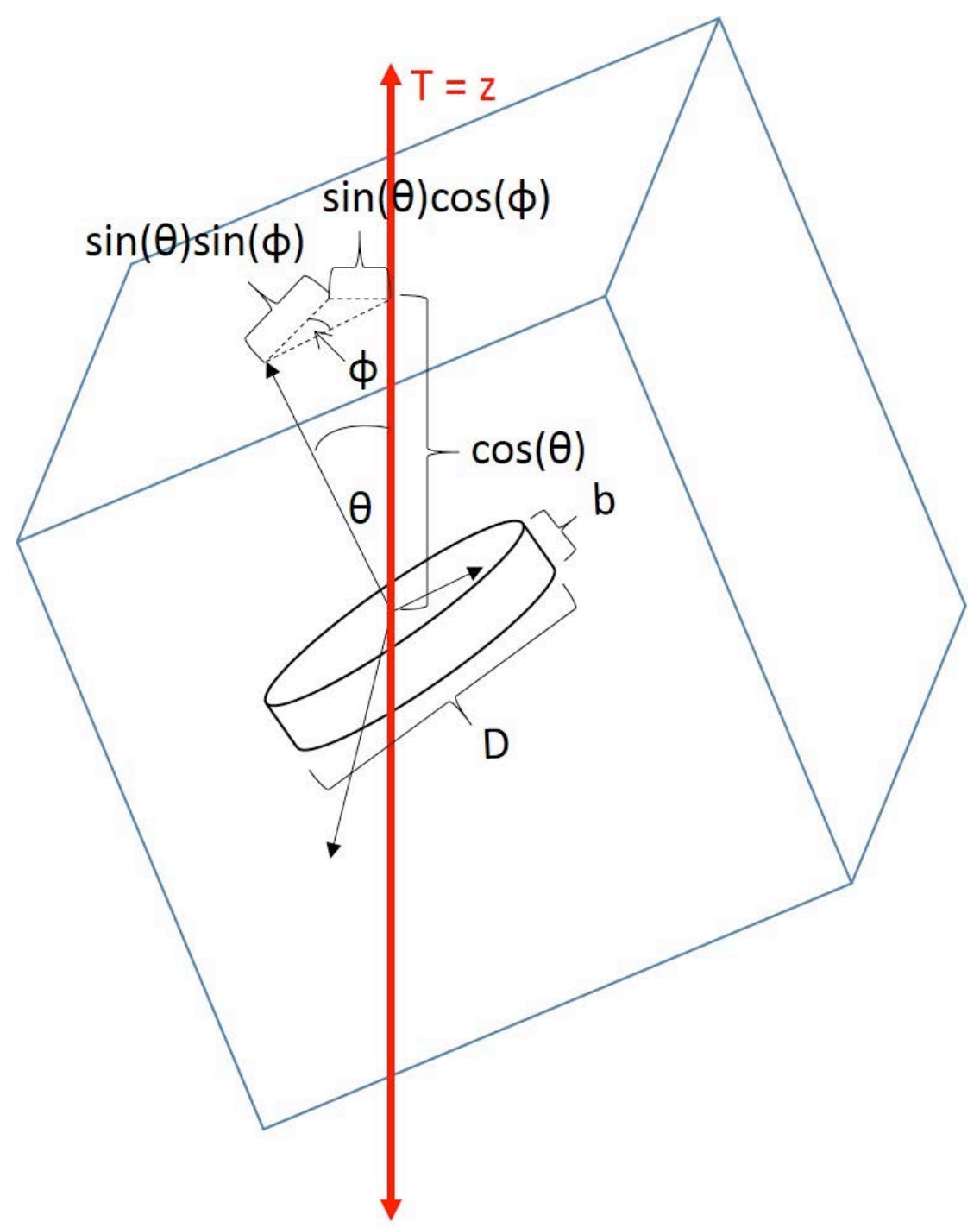

Figure 27. Orientation of a grain with dislocation loop to the tensile axis as defined by $\theta$, and $\phi$. 


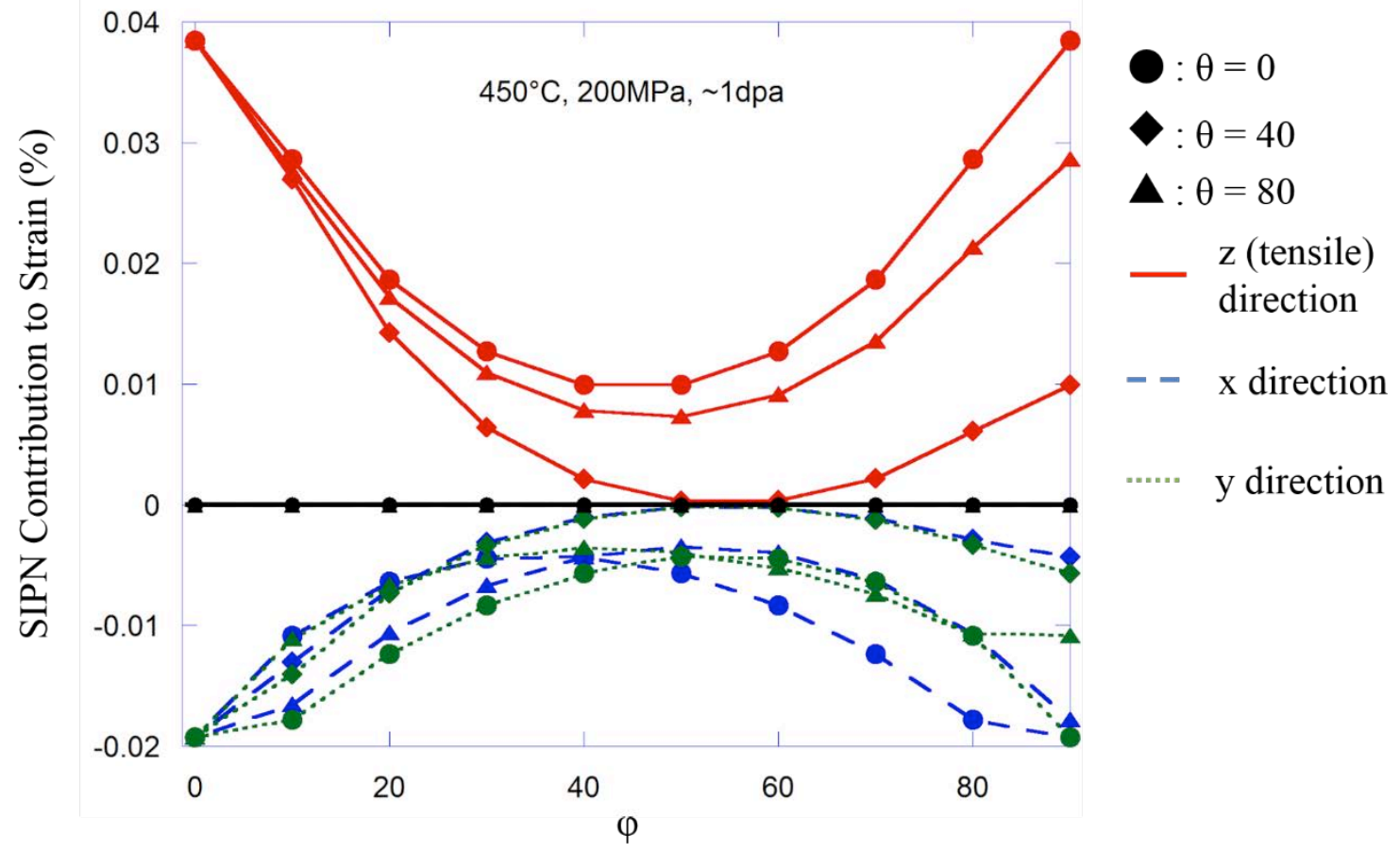

Figure 28. SIPN calculations as a function of the angles $\theta$ and $\phi$ dislocation loop make to the tensile axis for irradiation creep sample IT450200. 


\section{References}

1. Z. Jiao, V. Shankar, and G.S. Was, "Phase Stability in Proton and Heavy Ion Irradiated Ferritic-Martensitic Alloys" J. Nucl. Mater. 419 (2011) 52. *

2. Z. Jiao and G.S. Was, "Precipitate Evolution in Ion-Irradiated HCM12A" J. Nucl. Mater. 425 (2012) 105-111.*

3. P.J. Maziasz, J. Nucl. Mater. 169 (1989) 95-115.

4. M. K. Miller, Atom probe tomography: Analysis at the atomic level. (2000) NY: Kluwer Academic/Plenum Publishers.

5. S.I. Maydet, K.C. Russell. J. Nucl. Mater. 64 (1977) 101-114.

6. J.P. Wharry and G.S. Was, "A systematic study of radiation-induced segregation in ferriticmartensitic alloys," J Nucl Mater 442 (2013) 7-16. *

7. Y. Huang, J.P. Wharry, Z. Jiao, C.M. Parish, S. Ukai, and T.R. Allen, "Microstructural evolution in proton irradiated NF616 at $773 \mathrm{~K}$ to 3 dpa," J Nucl Mater 442 (2013) S800-S804. *

8. K.G. Field, L.M. Barnard, C.M. Parish, J.T. Busby, D. Morgan, and T.R. Allen, "Dependence on grain boundary structure of radiation induced segregation in a $9 \mathrm{wt} . \% \mathrm{Cr}$ model ferritic/martensitic steel," J Nucl Mater 435 (2013) 172-180. *

9. J.P. Wharry, Z. Jiao, and G.S. Was, "Application of the inverse Kirkendall model of radiation-induced segregation to ferritic-martensitic alloys," J Nucl Mater 425 (2012) 117-124. * 10. J.P. Wharry, Z. Jiao, V. Shankar, J.T. Busby, and G.S. Was, "Radiation-induced segregation and phase stability in ferritic-martensitic alloy T91," J Nuc. Mater. 417 (2011) 140-144. *

11. J.P. Wharry, "The mechanism of radiation-induced segregation in ferritic-martensitic alloys," Dissertation. The University of Michigan, 2012. *

12. J.P. Wharry and G.S. Was, "The mechanism of radiation-induced segregation in ferriticmartensitic alloys," Acta Mater, in press. *

13. C. $\mathrm{Xu}$ and G. S. Was, "In situ proton irradiation creep of ferritic-martensitic steel T91," J. Nucl. Mater., vol. 441, no. 1-3, pp. 681-687, 2013.

14. J. Matthews and M. Finnis, "Irradiation Creep Models - An Overview," J. Nucl. Mater., vol. 159, pp. 257-285, 1988.

15. E. M. Haney, F. Dalle, M. Sauzay, L. Vincent, I. Tournié, L. Allais, and B. Fournier, "Macroscopic results of long-term creep on a modified 9Cr-1Mo steel (T91)," Mat. Sci. Engin. A, vol. 510-511, pp. 99-103, Jun. 2009.

16. R. Okamoto and S. D. Harkness, "Stress-Based Loop Nucleation in Irradiated Type 316 Stainless Steel,” J. Nucl. Mater., vol. 48, pp. 204-206, 1973.

17. L. K. Mansur, "Irradiation creep by climb-enabled glide of dislocations resulting from preferred absorption of point defects," Phil. Mag., vol. 39, p. 497, 1979.

* denotes publications resulting directly from this project 


\section{Degrees Awarded}

Cheng Xu, Ph.D. 2014

Alicia Certain, Ph.D. 2012

Kevin Field, Ph. D. 2012

Janelle Wharry, Ph.D. 2012

\section{$\underline{\text { Publications }}$}

J. Wharry, G. S. Was, "The Mechanism of Radiation-Induced Segregation in Ferritic-Martensitic Alloys," Acta. Mater. (2104), in press.

Kevin G. Field, Brandon D. Miller, Heather Chichester, Kumar Sridharan, Todd R. Allen, Relationship Between Grain Boundary Structure and Radiation Induced Segregation in a Neutron Irradiated 9 wt. \% Cr Model Ferritic/Martensitic Steel, Journal of Nuclear Materials 445 (2014) 143-148.

A. Certain, H.-J. Lee Voigt, T.R. Allen, and B.D. Wirth , Investigation of cascade-induced resolution from nanometer sized coherent precipitates, J. Nucl. Mater. 432 (1-3) (2013) 281.

Y. Huang*, C. M. Parish, J. P. Wharry, Z. Jiao, S. Ukai, and T. R. Allen, Microstructural evolution in proton irradiated NF616 at 773K to 3 dpa, J. Nucl. Mater Volume 442, Issues 1-3, Supplement 1, November 2013, Pages S800-S804

K.G. Field, L.M. Barnard, C.M. Parish, J.T. Busby, D. Morgan, T.R. Allen, "Dependence on grain boundary structure of radiation induced segregation in a 9 wt. $\% \mathrm{Cr}$ model ferritic/martensitic steel," Journal of Nuclear Materials, Volume 435, Issues 1-3, April 2013, Pages 172-180.

A. Certain, S. Kuchibhatla, V. Shutthanandan, D. T. Hoelzer, T.R. Allen, Radiation Stability of Nanoclusters in Nano-structured Oxide Dispersion Strengthened (ODS) Steels, 434, (1-3) 2013 $311-321$.

C. Xu, G. S. Was, “In-situ Proton Irradiation Creep of Ferritic-Martensitic Steel T91,” J. Nucl. Mater. 441 (2013) 687-687.

Z. Jiao, G. S. Was, "Precipitate Evolution in Ion Irradiated HCM12A," J. Nucl. Mater., 425 (2012) 105-111.

J. Wharry, Z. Jiao, G. S. Was, "Application of the Inverse Kirkendall Model of RadiationInduced Segregation to Ferritic-Martensitic Alloys,” J. Nucl. Mater., 425 (2012) 117-124.

Z. Jiao V. Shankar, G. S. Was, "Phase Stability in Proton and Heavy Ion Irradiated FerriticMartensitic Alloys," J. Nucl. Mater. 419 (2011) 52-62. 
J. P. Wharry, Z. Jiao, V. Shankar, J. T. Busby, G. S. Was, "Radiation-induced Segregation and Phase Stability in Ferritic-Martensitic Alloy T91,” J. Nucl. Mater. 417 (2011) 140-144.

Z. Jiao, M. McMurtrey, G. S. Was, "Strain-induced Precipitate Dissolution in an Irradiated Austenitic Alloy," Scr. Mater., 65, No. 2 (2011) 159-162.

G. S. Was, J. P. Wharry, B. Frisbie, B. D. Wirth, D. Morgan, J. D. Tucker and T. R. Allen, "Assessment of Radiation-Induced Segregation Mechanisms in Austenitic and FerriticMartensitic Alloys," J. Nucl. Mater. 411 (2011) 41-50. 